CAHIER DE RECHERCHE \#1404E

WORKING PAPER \#1404E

Département de science économique

Department of Economics

Faculté des sciences sociales

Université d'Ottawa

Faculty of Social Sciences

University of Ottawa

\title{
Free-Riding on Energy Efficiency Subsidies: the Case of Natural Gas Furnaces in Canada
}

\author{
Nicholas Rivers $^{\dagger}$ and Leslie Shiell ${ }^{\ddagger}$
}

July 2014

\footnotetext{
* Acknowledgements: We thank Dominic Demers and Soodeh Saberian for providing excellent research assistance. We thank Denise Young and participants at the Canadian Resource and Environmental Economics workshop and the Empirical Methods in Energy Economics workshop for providing valuable comments. Rivers gratefully acknowledges funding from the SSHRC Canada Research Chairs program. We also thank Natural Resources Canada for providing the data used in this study as well as Susan Mowers for help with the census data.

${ }^{\dagger}$ Graduate School of Public and International Affairs, University of Ottawa, 120, University Private, Ottawa ON K1N6N5 Canada; e-mail: nrivers@uottawa.ca.

${ }^{\ddagger}$ Department of Economics, University of Ottawa, 120, University Private, Ottawa ON K1N 6N5 Canada; e-mail: leslie.shiell@uottawa.ca.
} 


\begin{abstract}
We assess the extent to which subsidies for home energy efficiency improvements in Canada have been paid to households that would have undertaken the improvements anyway - the socalled free rider rate. We focus on forced-air natural gas furnaces, replaced between April 1, 2007 and March 31, 2011, under both federal and provincial subsidy programs as well as the 2009 federal Home Renovation Tax Credit. Our results indicate that around 70 percent of expenditures under the Canadian subsidy and tax credit programs represented free riding. We estimate that the cost effectiveness of the programs in terms of greenhouse gas reduced was at least $\$ 100 / \mathrm{tCO}_{2}$, and potentially as high as $\$ 800 / \mathrm{tCO}_{2}$, depending on the assumptions made. Further, we find that a substantial majority of the grants were received by middle- and highincome households, such that the grant had a regressive effect on the distribution of income. We conclude that such grants are not an optimal way to improve residential energy efficiency.
\end{abstract}

Key words: household energy efficiency, subsidies

JEL classification: H2, Q4, Q5

\title{
Résumé
}

Nous évaluons la mesure dans laquelle les subventions pour l'amélioration de l'efficacité énergétique résidentielle au Canada ont été versées aux ménages qui auront entrepris les améliorations de toute façon - le soi-disant taux de resquillage. Nous nous concentrons sur les fournaises à air chaud pulsé au gaz naturel, remplacés entre le 1er Avril 2007 et le 31 Mars 2011, dans le cadre des programmes de subvention fédérale et provinciale ainsi que le crédit d'impôt pour la rénovation domiciliaire fédéral de 2009. Nos résultats indiquent que près de 70 pour cent des dépenses au titre des programmes de subventions et de crédits d'impôt canadiens représentait le resquillage. Nous estimons que le rapport coût-efficacité des programmes en termes de gaz à effet de serre était d'au moins 100 \$ / t de CO2, et potentiellement aussi haut que $800 \$$ / t de $\mathrm{CO} 2$, selon les hypothèses retenues. En outre, nous constatons que la majorité substantielle des subventions ont été reçues par les ménages à revenu moyen ou élevé, de sorte que la subvention a eu un effet régressif sur la répartition des revenus. Nous concluons que ces subventions ne représentent pas une politique optimale d'améliorer l'efficacité énergétique résidentielle.

Mots clés : l'efficacité énergétique résidentielle, les subventions

Classification JEL : H2, Q4, Q5 


\section{Introduction}

Home energy efficiency retrofits are generally considered one of the most cost effective options for significantly reducing greenhouse gas emissions and improving energy efficiency. For example, a recent analysis by McKinsey \& Company (2009) finds that a number of residential energy efficiency improvements including heating, insulation, lighting, and appliance retrofits have the potential to simultaneously save energy, reduce greenhouse gas emissions, and lower costs of energy services. Even so, uptake of residential energy retrofits is often lower than expected. To address this "energy efficiency gap," a number of countries offer subsidies, grants, or tax rebates to encourage uptake. Focusing on a Canadian program that provided grants to encourage home energy retrofits over a number of years, this study provides one of the few quantitative evaluations of large-scale energy efficiency retrofit programs to date. We find that a significant proportion of the total funds allocated to the program were spent on providing subsidies to households that would have completed the upgrade even without the subsidy. As a result, we conclude that the program was an expensive way to reduce greenhouse gas emissions. We also find that retrofit grants were predominantly received by wealthy households, such that the program had a regressive impact on the distribution of income.

Economists have investigated the so-called energy efficiency gap - the difference between the actual diffusion of energy-saving products and that which would be expected if consumers made all energy-saving investments with positive net present value - for decades. Early empirical analysis diagnosed the gap with the observation that implicit discount rates applied by consumers for the purchase of energy-consuming durables were higher than for other investments of similar risk (Hausman, 1979; Train K. , 1985). More recent studies incorporate elements of behavioral economics to explain the energy efficiency gap. Using modern econometric techniques and large data sets, these studies suggest that other explanations for the gap include consumer heterogeneity, hidden costs, uncertainty, as well as behavior anomalies such as inattention, habit formation, and biased beliefs (Allcott \& Greenstone, 2012; Gillingham \& Palmer, 2014).

Although it is difficult to precisely quantify the magnitude or even presence of an energy efficiency gap, suspicion that it is large has influenced the design and application of energy and environmental policy. Such policies take on a number of forms. Information policies are used by governments and utilities to inform households and firms of cost-effective opportunities for 
saving energy. Such policies include provision of low-cost audits to firms and households as well as development of energy efficiency labels. Regulations are also widely applied to improve energy efficiency. In developed countries, most household appliances must meet minimum energy efficiency standards in order to receive permission to be sold. Governments also frequently offer financial incentives, including subsidies and tax credits, to encourage consumers to make energy efficient choices regarding new equipment, materials and building alterations.

One of the more prominent financial incentives for encouraging energy efficiency improvements takes the form of residential retrofit subsidies. In Canada, at the federal level, both Liberal and Conservative governments have implemented subsidy programs designed to encourage homeowners to retrofit their homes to improve energy efficiency. At the provincial level, a number of provinces have offered subsidy programs for residential energy efficiency retrofits, typically piggybacking on the federal programs. In addition, grant programs have been offered by electric and natural gas utilities.

Our focus in this paper is on evaluating residential retrofit grants offered between 2007 and 2011 in Canada. We concentrate on natural gas furnace retrofits, since these are a both major source of potential energy efficiency improvements as well as being relatively homogeneous, which facilitates analysis. Our analysis uses a large and detailed administrative data set, which we believe is unique to the evaluation of residential retrofit programs. We have detailed information on demographic and building characteristics for almost 400,000 households that participated in the program, which is the entire population of program participants for the period we consider. We observe retrofit choices for each of these households. We identify the effect of residential retrofit grants on natural gas furnace choice through the significant spatial and temporal variation in retrofit grants in the data.

We estimate discrete choice models to determine the sensitivity of natural gas furnace choice to changes in subsidy rates or operating costs. Using our estimated coefficients, we simulate a counterfactual scenario in which retrofit grants are not offered. By comparing this scenario with actual furnace choices, we are able to estimate what proportion of high efficiency natural gas furnaces purchased during the sample timeframe were due to the retrofit grants, and what proportion would have occurred regardless. Our simulations suggest that around 70 percent of the subsidies were received by homeowners that would have adopted the high efficiency 
furnaces even without the subsidy. This high level of free-ridership worsens the costeffectiveness of the program from the government's perspective. ${ }^{1}$

We extend our analysis in two other directions. First, we couple the administrative database with census information on income. This allows us to estimate the incidence of the program according to household demographics. We find that the program targets middle- and high-income households, and excludes low-income households, primarily because high-income households are more likely to own their home than low-income households. Second, we estimate the impact of the program on energy consumption and greenhouse gas emissions. Our findings suggest that the program reduced greenhouse gas emissions by between 0.5 and $3 \mathrm{Mt}$ $\mathrm{CO}_{2}$ in total. We compare the $\mathrm{CO}_{2}$ reductions achieved by the program to the cost of the program, and find that the program had a cost effectiveness of between $\$ 100 / \mathrm{t}$ and $\$ 800 / \mathrm{tCO}_{2}$, depending on assumptions relating to the timeframe of the analysis and the costs included in the evaluation. In any case, the program appears to be an expensive way for government to achieve greenhouse gas reductions.

Our paper is closely related to a handful of others that analyze the effects of residential energy efficiency subsidies on adoption of new technologies. Hartman (1988) uses a data set from a US electric utility that includes demographic data and electricity consumption data for a population that includes both participants and non-participants in a utility energy conservation program. With a two-stage regression covering both the program participation decision and the conservation decision, he estimates that about 45 percent of the electricity savings attributed to the program would have occurred even in the absence of such a program. Revelt and Train (1998) estimate a mixed logit model, combining a stated preference choice experiment on consumer choice of appliance efficiency under various levels of subsidy with revealed preference data on actual appliance choice. When simulating the effect of a subsidy program using their estimated model, they find that the proportion of adopters of energy efficient appliances increases by about 8.5 percent, but that subsidies are paid to 15.8 percent of the population, suggesting a free-ridership rate of 46 percent. Train and Atherton (1995) use the same data set to estimate a nested logit model, again combining revealed preference and stated preference data.

\footnotetext{
${ }^{1}$ From a social efficiency perspective, free-ridership is not a first-order concern, since it simply reflects a transfer between agents. Nevertheless, we feel that there are two important reasons that it is important to estimate freeridership. First, funds for providing energy efficiency grants must be generated from taxes, which themselves impose efficiency costs, so there is a social cost to inefficient tax use. Second, governments have limited budgets for particular programs, and free-ridership limits the effect of programs that are constrained to a particular budget.
} 
They estimate free ridership rates of 36 percent for refrigerator programs and 66 percent for air conditioner programs. Grösche and Vance (2009) use a conditional logit technique and estimate a free ridership rate of about 50 percent for a recent German retrofit program. A re-analysis of the same data using a nested logit approach by Grösche, Schmidt, and Vance (2009) finds freeridership rates of over 90 percent for a modest home retrofit subsidy and 70 percent for a more substantial incentive program. Cameron (1985) conducts a similar analysis using data on US housing retrofits. She finds free ridership rates of up to 86 percent when house retrofit subsidies worth 15 percent of the cost of the measure are provided. Overall, previous studies suggest that a large proportion of the recipients of this type of subsidy program are consumers that would have adopted the technology even without the subsidy. As a result, the cost-effectiveness of this type of program is generally fairly poor.

Our paper builds on this prior literature in at least two respects. First, our analysis is based on a large administrative database. In contrast, much of the prior literature uses much smaller data sets, and these are often derived from surveys rather than from program administrative records. Our large data set helps us provide precise parameter estimates, and the fact that it is from administrative records helps us get around problems of recall that can affect survey data on home retrofits. Second, our data set covers a program that offered financial incentives of varying size, with variation occurring both between regions and over time, while the basic structure of the program remained constant. This variation provides us with a compelling means to identify the effect of subsidies on retrofit choices.

The paper proceeds as follows. Section 2 outlines the energy efficiency programs that are analyzed in this paper. Section 3 presents the data used for the program evaluation. Section 4 presents a theoretical and empirical model for estimating the effect of a rebate program on a household's choice of natural gas furnace, and section 5 presents the results of the evaluation. Section 6 presents the results of a simulation exercise using the estimated model coefficients to estimate the cost-effectiveness and environmental impact of the EcoEnergy program. Finally, section 7 concludes.

\section{EcoEnergy Home retrofit program}

The EcoEnergy - Homes (EEH) program was announced as part of a suite of EcoEnergy programs by the federal government in 2006 . The EEH program was similar in structure to a 
prior federal government program, and so represents one element of a decade-long policy aimed at improving residential energy efficiency in Canada. The EEH program was in place between April 2007 and March 2012. In total over 640,000 homeowners received incentives through the EEH program, and total program spending was close to $\$ 1$ billion. ${ }^{2}$ In this section, we describe salient features of the program, with a particular focus on those that are relevant to our econometric analysis.

The EEH program provided grants of up to $\$ 5,000$ to help homeowners make their homes more energy efficient. To participate in the program, participants were required to obtain an energy efficiency audit by a certified third-party auditor using the EnerGuide Rating system prior to beginning any retrofit work. ${ }^{3}$ The audit consisted of a blower-door test to measure air leakage rates, as well as a detailed characterization of the building envelope and heating and cooling equipment. Based on the results of the audit, each household participating in the EEH program was offered a set of retrofit options that qualified for energy efficiency grants. For instance, a house with an older and less efficient furnace would be provided with the option of receiving a grant conditional on purchasing a more efficient furnace. In general, grants were only available for the most efficient equipment, and were conditional on the new equipment being higher efficiency than the equipment being replaced. If households elected to adopt recommendations suggested by the audit, they were required to obtain a follow-up audit to confirm installation of the energy efficiency equipment before receiving the grant.

In addition to the federal EEH program, several provincial governments and energy utilities offered grants for energy efficiency retrofits during the period for which we have data. Natural Resources Canada, which implemented the EEH program, coordinated agreements with these provincial governments and energy utilities. In each case, these coordinated agreements built on the federal EEH program, to increase grants available for certain types of home energy retrofits in a particular region at a particular time. The coordinating agreements allowed

\footnotetext{
${ }^{2}$ Summary statistics relating to the program are available in an archived government web page: https://www.nrcan.gc.ca/energy/efficiency/housing/home-improvements/5019\#g13. Note that the \$1 billion estimate is for the federal EEH program only; provincial grants coordinated with the EEH program are not included in this total. The $\$ 1$ billion estimate also applies to all types of retrofits covered by the program, whereas this paper focuses just on natural gas furnaces.

${ }^{3}$ The federal EEH program did not cover the costs of home energy audits, which typically were about $\$ 300$. A previous iteration of the home energy retrofit program did subsidize audit costs. Some provincial governments also offered subsidies to help households cover audit costs.
} 
provinces to leverage the auditing and reporting structure already in place as part of the federal EEH program and provide additional funding for certain types of retrofits.

On top of these energy efficiency retrofit programs, the federal government offered a temporary Home Renovation Tax Credit (HRTC), covering all types of home renovations (including energy efficiency renovations). The HRTC was a non-refundable credit offered by the federal government on personal income taxes during the 2009 tax year. The value of this credit varied by household, depending on the level of taxable income and the amount of total renovation expenditures of the household. In particular, the credit was based on the portion of expenditures in excess of $\$ 1,000$ up to $\$ 10,000$ (i.e. a maximum base for the credit of $\$ 9,000$ ). This amount was multiplied by the credit rate of 0.15 , yielding a maximum potential value of the HRTC to a household of $\$ 1,350$. However, the value of the credit for a furnace purchase was typically much less, since prices for furnaces are generally below $\$ 7,000$, and many households may have claimed part or all of the credit for other renovation expenditures. Using $\$ 6,000$ as the maximum base for the credit (i.e. $\$ 7000$ - \$1000) yields a maximum potential value of the HRTC for a furnace purchase of $\$ 900$. We include this program when we simulate the effect of subsidies later in the paper. ${ }^{4}$

The EEH and complementary provincial programs provided grants for a wide variety of home energy retrofits, including heating, cooling, and ventilation equipment, hot water systems, insulation, air sealing, and improvements in doors, windows, skylights, and toilets. The analysis of household choices under these programs is complicated by the wide variety of options available within each category (e.g. multiple types of heating equipment), as well as the fact that different households can choose different combinations of improvements. For example, some households may replace their heating equipment only, some may replace heating equipment plus insulation, some may replace insulation and windows but not heating equipment, etc. A comprehensive analysis of household choice would prove to be extremely demanding in terms of the amount of information required, since statistical analysis requires estimating operating cost savings associated with each combination of improvements, for each household, not just the choice actually made. For that reason, we have chosen to focus on one type of energy efficiency improvement only, namely choices relating to forced-air natural gas furnaces. As a result, we

\footnotetext{
${ }^{4}$ The manner in which we impute the value of the HRTC for each household is discussed in the appendix.
} 
filter the program data to include only households for which the original and final heating equipment is a natural gas furnace. ${ }^{5}$

There are a number of important features of the program and the data. First, as described above, by using a pre-retrofit audit, the EEH program is able to make grants conditional on existing equipment. The program does this by only providing grants in instances where household energy efficiency is improved as a result of a retrofit decision. For example, a household replacing an (old) energy efficient air conditioner with a new one of similar efficiency would not qualify for a grant. This feature of the program is aimed at ensuring that a higher fraction than otherwise of the grants go to households that make energy efficiency investments additional to what they would have done without the program, i.e., minimize free-ridership.

Second, because of the detailed audits that are required both before and after the retrofit, there exists data on exactly what equipment was in place before the retrofit as well as after. In total, we have data on around one hundred variables describing the physical house and equipment characteristics both before and after retrofit. We use a portion of this data directly and a large portion indirectly to conduct a statistical evaluation of the program. ${ }^{6}$

Third, although the program framework remains unchanged during the period covered by our analysis, incentives available to consumers are varied. In particular, there is substantial variation both over time and across provinces in the level of incentives available for various retrofit decisions. We use this cross-sectional and time-series variation in retrofit incentives to identify the effect of financial incentives on household retrofit decisions.

Figure 1 illustrates the variation in furnace grants by furnace type, province, and time. Combined federal-provincial grants varied from a low of $\$ 0$ for inefficient furnaces to a high of $\$ 1,740$ for replacement of a non-condensing furnace with a 95 percent AFUE furnace with a DC motor in British Columbia. As can be seen from the figure, there are a large number of changes in grant levels both over time, across furnace types, and between provinces. We use this substantial variation in furnace grants, which is exogenous to an individual homeowner, to identify the sensitivity of furnace choice to financial incentive.

\footnotetext{
${ }^{5}$ This condition is not particularly restrictive - most households in our sample use natural gas for heating. Details on the data set compilation are in the Appendix.

${ }^{6}$ Our measure of energy consumption is derived from building simulation software that uses the reported building characteristics as inputs.
} 


\section{Data}

We obtain administrative data that covers the entire population of EEH program participants from April 1, 2007 through March 31, 2011 from Natural Resources Canada. The data includes detailed information on the physical house characteristics and main energy-using appliances for each program participant. For example, the data includes measurements of room sizes, wall types, number and type of windows, as well as furnace and air conditioner characteristics. The data also includes information on air leakage gathered from a blower-door test. In total, there are over one hundred house characteristics recorded for each house. Based on these characteristics as well as the geographic location of the house, building simulation software is used to estimate heating requirements for the household; this estimate is also included in the database. ${ }^{7}$

We focus on natural gas furnaces in this paper, and restrict our sample to the provinces of BC, Alberta, Saskatchewan, Manitoba and Ontario where natural gas infrastructure exists. The $\mathrm{EEH}$ database records the original (pre-retrofit) as well as the new (post-retrofit) furnace equipment (these are identical if the household did not replace the furnace). Included in the database (for both pre-retrofit and post-retrofit) are the furnace type and model number, fuel type, rated furnace efficiency, annual fuel utilization efficiency (AFUE), a flag indicating the presence of a DC fan motor, and estimated annual fuel consumption. ${ }^{8}$

The original program database with which we work includes 396,595 program participants. We drop observations that do not use natural gas furnaces, observations that are not in Ontario and the Western provinces, and observations in which there appear to be coding errors for dates and natural gas prices. This leaves us with a database of 328,688 observations that we use in the empirical analysis. Each observation corresponds to one participating household, and each household is a single-family dwelling.

We supplement the administrative data with other sources. First, we create a database consisting of natural gas furnace grants offered under the EEH program by the federal government, as well as grants offered by provincial governments and energy utilities during this

\footnotetext{
${ }^{7}$ Estimates of energy use are produced from the HOT2000 building simulation software.

${ }^{8}$ The AFUE is an estimate of the ratio of useful thermal energy output to fuel energy input, averaged over the full year. It differs from the rated (peak) efficiency in that it accounts for the actual operation cycle of a typical furnace. It is thus the preferred measure of energy efficiency for the equipment as it is actually used. Incentives in the federal and provincial retrofit grant programs are based on AFUE ratings.
} 
same time frame. ${ }^{9}$ These data were taken from the brochures for the corresponding programs as well as personal communications with the various Ministries and utilities, which were responsible for these programs. The full grant database is included as Appendix 1. The grant database is merged with the program database so that grants available to each household in the dataset, depending on furnace choice, geography, and date, are captured.

Second, we merge the EEH database with the 2006 Census database. Observations in the EEH database are each associated with a postal code (some observations are missing postal codes). Postal codes are high-resolution 6-digit geographic indicators. Using household postal codes, we merge with census data to obtain a demographic profile of households participating in the EEH program. The census data includes a large number of variables, but our focus is on income. The census data is available at the level of census dissemination areas, which contain on average 400-700 individuals. As a result, our measure of income is an average income at the census dissemination area level. The income measure we use is the average income for individuals aged 15 years and older, and we focus on total income (including government transfers).

Figure 2 and Figure 3 summarize total grants for energy efficient furnaces provided as part of the EEH and complementary provincial programs. A small number of grants were provided in 2007 and 2008, and a much larger amount in 2009 and 2010. In total, over \$400 million in grants were provided to encourage Canadians to adopt more energy efficient natural gas furnaces in the four-year period between April 1, 2007 and March 31, 2011. Figure 2 shows that the large majority of grants were made to Ontario residents. This is partly because Ontario is by far the largest province amongst those in our data, but also because grants in Ontario were relatively generous compared to most other provinces. Figure 3 shows the breakdown of grants by source. The federal EEH program, provincial cooperating programs, and the federal Home Renovation Tax Credit program each contributed roughly equal amounts to the total subsidy funding during the period analyzed. Provincial grants were more generous in later years, and the federal HRTC was only available in 2009 and 2010. As a result, total grants were significantly higher in these two years than in other years.

Table 1 shows summary statistics for several of the main variables in our data set. Three quarters of program participants are from Ontario, roughly 8 percent are from each of the three

\footnotetext{
${ }^{9}$ Participating utilities in our sample include BC Hydro, Fortis BC, SaskEnergy, and Manitoba Hydro.
} 
Western provinces, and about 3 percent are from Manitoba. The average income of all individuals aged 15 and greater (at the neighborhood level) for program participants is about $\$ 40,000$. The average household is estimated to spend about $\$ 1,880$ on natural gas prior to program participation, and about $\$ 1,665$ after program participation, reflecting an improvement in average furnace AFUE from 80 percent to approximately 91 percent. On average, participating households received nearly $\$ 500$ in furnace retrofit subsidies from the provincial government, and an additional $\$ 400$ in federal government EEH subsidies. In addition, the average household in our sample received \$438 in HRTC tax credits.

\section{Model}

\subsection{A theoretical model of furnace replacement}

We sketch out a simple theoretical model of a household's furnace choice in order to inform our empirical work later in the paper. Let $t=1,2, \ldots$ represent time, measured in years, and $j=1,2, \ldots$ represent the furnace generational index (i.e. the households' first furnace, second furnace, etc.). Now define $v_{t}$ as the vintage (year of use) of the household's furnace at time $t^{10}$

A household's heating costs are a function of the technical efficiency of the furnace, the choice of temperature setting, the physical characteristics of the house, and the price of fuel. Let $e^{j}$ represent the household's efficiency choice for its $j^{\text {th }}$ furnace. ${ }^{11}$ Let $T_{t}$ represent the household's temperature selection. Define $z$ as a vector of exogenous house characteristics (e.g. size, climatic variables, effectiveness of the thermal envelope), $\pi_{t}$ as the price of natural gas, and $r$ as the discount rate. Then we define annual operating cost $c_{t}=c\left(e, T_{t}, z, \pi_{t}\right)$ as a function of efficiency, temperature selection, exogenous house characteristics and fuel price.

Capital cost $q_{t}=q(e, z, t)$ is defined as a function of efficiency, exogenous house characteristics, and time. Inclusion of time as an independent variable accounts for exogenous variations in market conditions affecting the purchase price of a given model of furnace. Prices are increasing in the level of energy efficiency, i.e. $\frac{\partial q(e, z, t)}{\partial e}>0$, which explains the persistence

\footnotetext{
${ }^{10}$ Vintage is distinct from age. Age is commonly used to indicate the number of anniversaries attained; i.e. age equals $v_{t}-1$. We suppress the $t$ subscript in the subsequent exposition except where it is necessary to avoid confusion.

${ }^{11}$ Furnace efficiency is measured by AFUE (annual fuel utilization efficiency), where 100 represents complete efficiency, i.e. total capture of all fuel energy for heating purposes. Where it doesn't lead to confusion, we drop the $j$ superscript subsequently.
} 
of low efficiency models in the market. The total value of retrofit subsidies available at $t$ is denoted $s(e, t)$ and differentiated by efficiency level.

One of the most important features of a household's plan for furnace replacement is uncertainty about the possibility of a breakdown. Define $p_{v}$ as the probability that the furnace breaks down irreparably during its $v^{\text {th }}$ year. By definition $\sum_{v=1}^{\infty} p_{v}=1$. Next, define $\sigma_{v}$ as the probability that the furnace will survive to its $v^{\text {th }}$ anniversary (end of $v^{\text {th }}$ year). The two variables are related as $\sigma_{v}=\sum_{s=v+1}^{\infty} p_{s}$. Then define $D_{v}=\frac{p_{v+1}}{\sigma_{v}}$ as the probability of breakdown during the $v+1^{\text {th }}$ year conditional upon survival to the $v^{\text {th }}$ anniversary. It follows that $1-D_{v}=\frac{\sigma_{v+1}}{\sigma_{v}}$ is the probability that a furnace will last until its $v+1^{\text {th }}$ anniversary conditional on lasting to its $v^{\text {th }}$ anniversary. $^{12}$

If the furnace is kept in operation until it breaks down, the expected present-value cost of a furnace of efficiency level $e$ purchased at time $t$ is

$$
\begin{gathered}
V\left(e, z, t,\left\{T_{s}\right\}_{s=t}^{\infty},\left\{\pi_{s}\right\}_{s=t}^{\infty}\right)=q(e, z, t)-s(e, t)+\sum_{v=1}^{\infty} p_{v} \sum_{s=1}^{v} \frac{c\left(e, T_{t+s-1}, z, \pi_{t+s-1}\right)}{(1+r)^{s}} \\
=q(e, z, t)-s(e, t)+\sum_{v=0}^{\infty} \sigma_{v} \frac{c\left(e, T_{t+v}, z, \pi_{t+v}\right)}{(1+r)^{v+1}}
\end{gathered}
$$

and the expected age of the furnace at breakdown is $\sum_{v=1}^{\infty} p_{v} v$. Now define the household's income stream and consumption plan as $\left\{y_{t}\right\}$ and $\left\{x_{t}\right\}$ respectively (i.e. consumption other than heating service). If the homeowner only replaces a furnace after a breakdown (involuntary replacement), then her decision problem is to jointly choose $\left\{e^{j}\right\},\left\{T_{t}\right\}$, and $\left\{x_{t}\right\}$ by selecting furnaces with expected longevity $\sum_{v=1}^{\infty} p_{v} v$ to maximize lifetime utility subject to $\left\{y_{t}\right\}$ and (1).

However, there are a couple of reasons why the homeowner may prefer to voluntarily replace the furnace before it breaks down. First, the homeowner may wish to avoid costs, $B_{n}$, associated with breakdown, such as the inconvenience of unexpected loss of heating or additional costs associated with temporary electric heating. Second, the homeowner may wish to benefit from reductions in annual operating costs which can be achieved by purchasing a more efficient furnace.

Consideration of the best vintage at which to voluntarily replace a furnace turns the homeowner's decision into an optimal stopping time problem. Define $R^{1}$ as the optimally chosen anniversary to voluntarily replace the current furnace. More generally, let $\left\{R^{j}\right\}$ represent the set

\footnotetext{
12 The uncertainty notation is due to Cropper and Freeman (1991).
} 
of optimally planned replacement dates, where $R^{j}$ refers to the household's $j^{\text {th }}$ furnace replacement.

The derivation of $\left\{R^{j}\right\}$ is based on pairwise comparisons of voluntary replacements at the $v^{\text {th }}$ and $(v+1)^{t h}$ anniversaries. If the household undertakes a voluntary replacement of a furnace at the $v^{\text {th }}$ anniversary, the present value of cost for the year is ${ }^{13}$

$q\left(e^{2}, z, t\right)-s\left(e^{2}, t\right)+\frac{c\left(e^{2}, T_{t}^{2}, z, \pi_{t}\right)}{1+r}+p_{1} \frac{B+q\left(e^{3}, z, t+1\right)-s\left(e^{3}, t+1\right)}{1+r}$

The last term reflects the possibility that the new furnace breaks down within the year. In practice, $p_{1}$ is likely small enough that we can ignore this term. ${ }^{14}$ If instead the household delays a voluntary replacement until the $(v+1)^{\text {th }}$ anniversary, the present value of cost for the year is

$\frac{c\left(e^{1}, T_{t}^{1}, z, \pi_{t}\right)}{1+r}+D_{v} \frac{B}{1+r}+\frac{q\left(e^{2}, z, t+1\right)-s\left(e^{2}, t+1\right)}{1+r}$.

Comparing (2) and (3), we observe that the household prefers to undertake a voluntary replacement at the $v^{\text {th }}$ anniversary if and only if

$\left[q\left(e^{2}, z, t\right)-s\left(e^{2}, t\right)\right]-\left[\frac{q\left(e^{2}, z, t+1\right)-s\left(e^{2}, t+1\right)}{1+r}\right]<\frac{c\left(e^{1}, T_{t}^{1}, z, \pi_{t}\right)-c\left(e^{2}, T_{t}^{2}, z, \pi_{t}\right)}{1+r}+D_{v} \frac{B}{1+r}$,

i.e. the net opportunity cost of purchasing the furnace one year earlier (left-hand side) is less than the combined benefits of one year's savings on operating cost and the expected savings on breakdown cost (right-hand side). ${ }^{15}$ Note that, even if operating-cost savings and breakdown costs are zero, the household will still wish to voluntarily replace the furnace if $\left[q\left(e^{2}, z, t\right)-\right.$ $\left.s\left(e^{2}, t\right)\right]<\left[\frac{q\left(e^{2}, z, t+1\right)-s\left(e^{2}, t+1\right)}{1+r}\right]$, which may arise as a result of subsidies offered at $t .{ }^{16}$ Thus, there are three potential drivers of voluntary replacement: (i) reducing operating costs, (ii) avoiding breakdown costs, and (iii) saving on capital cost as a result of a short-lived subsidy.

Conducting pairwise comparisons for all values of $v$ identifies the optimal replacement choices. For example, $R^{1}$ is the earliest anniversary for which (4) is satisfied, conditional upon the values of $e, T, \mathrm{z}, \pi, \mathrm{r}$, and $B$. Formally

\footnotetext{
${ }^{13}$ Operating and breakdown costs are paid on the $v+1$ anniversary. It is assumed that operating costs are not affected by the breakdown for the remainder of the year, or alternatively that $B$ represents the net effect on operating costs for the remainder of the year.

${ }^{14}$ Moreover, the capital cost to the household of such a breakdown would be zero if the furnace were under warranty.

${ }^{15}$ In the special case where $e^{1}=e^{2}$ and the net purchase costs are the same at $t$ and $t+1$, (4) reduces to the highly intuitive condition $r\left[q\left(e^{2}, z, t\right)-s_{t}\left(e^{2}\right)\right]<D_{v} B$; i.e. the opportunity cost is less than the expected breakdown cost of delaying the purchase by one year.

${ }^{16}$ This result will also be more likely to hold in an environment of low interest rates (low $r$ ).
} 


$$
\begin{aligned}
& R^{1}\left(e^{1}, e^{2},\left\{T_{t}\right\}, z,\left\{\pi_{t}\right\}, r, B\right)= \\
& \min \left\{v \mid\left[q\left(e^{2}, z, t\right)-s\left(e^{2}, t\right)\right]-\left[\frac{q\left(e^{2}, z, t+1\right)-s\left(e^{2}, t+1\right)}{1+r}\right]<\frac{c\left(e^{1}, T_{t}^{1}, z, \pi_{t}\right)-c\left(e^{2}, T_{t}^{2}, z, \pi_{t}\right)}{1+r}+D_{v} \frac{B}{1+r}\right\}
\end{aligned}
$$

We note that the right-hand side of (4) is increasing in $v$, through $D_{v}$. Thus, a household with an older furnace is more likely to satisfy (4) ceteris paribus and therefore more likely to voluntarily purchase a new furnace in order to pre-empt a breakdown.

We now re-define the present-value cost of a new furnace as

$V^{*}\left(e, z, t, R^{1},\left\{T_{s}\right\}_{s=t}^{\infty},\left\{\pi_{s}\right\}_{s=t}^{\infty}\right)=q(e, z, t)-s(e, t)+\sum_{v=0}^{R^{1}-1} \sigma_{v} \frac{c\left(e, T_{t+v}, z, \pi_{t+v}\right)}{(1+r)^{v+1}}$,

which takes account of the optimally planned replacement date. The household's decision now is to jointly choose $\left\{R^{j}\right\},\left\{e^{j}\right\},\left\{T_{t}\right\}$, and $\left\{x_{t}\right\}$ to maximize lifetime utility subject to $\left\{y_{t}\right\}$, (5) and (6).

In the remainder of the paper, we focus on the household's choices of $R^{j}$ and $e^{j}$. For simplicity, we assume $T_{t}$ remains constant, an unavoidable assumption since we have no data reflecting choices of this value. As we explain later in the paper, we do not believe this materially affects our results. For now, we focus on voluntary replacements; we take up the case of involuntary replacements below. The implementation of a subsidy program may affect a household's choice of efficiency level of a new furnace as well as the timing of the purchase. It may also affect the desired longevity of the new furnace as well as the efficiency level of subsequent furnace replacements.

Figure 4 illustrates the solution $\left\{R^{j}, e^{j}\right\}$ to the household's optimization problem. We consider how the household's timing and choice of efficiency is influenced by availability and timing of subsidies. In panel (a), we show household choice when no subsidy is available. For simplicity, we show the efficiency levels and planned longevity of the successive furnaces as identical. In reality, of course, these choices might vary, as the household's income and other factors might be expected to vary over time.

In Figure 4 (b), we show a subsidy for energy efficient furnaces offered during the interval $\left[t_{1}, t_{2}\right]$ having two effects. First, the household increases its energy efficiency choice $e$ for the affected furnace, and second it moves forward the optimal date of replacement from the originally planned date corresponding with $R^{1}$ to the new date corresponding with $\hat{R}^{1}$. The increase in efficiency level follows directly from standard investment theory, whereby a 
reduction in the net cost of a particular model of capital good increases the discounted net benefit of the model and therefore the probability that it will be chosen. The movement forward of the optimal replacement date follows from the effect of the subsidy on condition (4). We note that an increase in the subsidy $s\left(e^{2}, t\right)$ reduces the opportunity cost of purchasing a new furnace at that time (left-hand side) and therefore increases the probability that (4) is satisfied.

Note that even if there is an equal increase in subsidy at $t$ and $(t+1)$, the overall effect is to reduce the left-hand side of (4) and increase the likelihood of moving forward the replacement date. The household prefers to take the subsidy earlier, due to the time value of money. We illustrate this result in Figure 4 (b) with the longer subsidy interval $\left[t_{1}, \hat{t}_{2}\right]$ which includes the originally planned replacement date corresponding with $R^{1}$.

In Figure 4 (c), the implementation of a subsidy program motivates the household to move forward the planned replacement date without changing the efficiency level from what would have been chosen under the original plan at $R^{1}$ (i.e. the household would have increased efficiency to the new level anyway). This is the classic case of a free rider - a household which claims the subsidy without affecting the efficiency level chosen. It is also possible to obtain freerider outcomes in which the original replacement date falls within the subsidy interval and is not affected by the subsidy.

In panel (d) of Figure 4, we show a household whose choices are not affected by the subsidy program. The deciding factor for this household is that it has a relatively young furnace when the program is implemented and therefore the subsidy is not large enough to induce it to deviate from its original plan.

The discussion so far has focused on voluntary replacements. An involuntary replacement may also receive a grant if (i) the furnace breaks down (or is condemned) during the subsidy interval $\left[t_{1}, t_{2}\right]$, (ii) the household completes the pre- and post retrofit audit, and (iii) the new furnace is of a high enough efficiency level to be eligible. The outcomes depicted in panels (b) and (c) of Figure 4 also apply to involuntary replacements, with the difference that the change in replacement date from $R^{1}$ to $\hat{R}^{1}$ is forced on the household rather than optimally chosen. Changes in subsequent planned replacement dates, e.g. $R^{2}$ to $\hat{R}^{2}$, are chosen optimally, as these refer to voluntary rather than involuntary replacements.

Consideration of (4) reveals that the receipt of a subsidy may also increase the desired longevity of the new furnace, compared with the original plan without subsidies, provided the 
household is not a free-rider. Once the new furnace is purchased, it becomes furnace 1 in condition (4). For a non-free rider, the subsidy results in a higher value of $e^{1}$ and therefore a lower value of the operating cost, $c\left(e^{1}, T^{1}, z, \pi\right)$. The lower operating cost reduces the likelihood that (4) is satisfied at the original replacement date $R^{1}$; if it is not satisfied, the household will seek to extend the life of the furnace. As a result, $D_{v}$ rises until condition (4) is once again

satisfied, and the furnace is replaced at a new, later date. In effect, the household wishes to extend the life of the high efficiency furnace to benefit from the reduced operating costs for a longer period of time.

Ultimately, the magnitude of this effect on longevity is an empirical question. However, we have reason to believe that it is quite small. First of all, this effect should be non-existent for free-riders, since these households do not change efficiency levels. Second, a desired increase in longevity of the subsidized furnace does not necessarily translate into an actual increase, since the household still faces a probability $D_{v}$ of an involuntary breakdown. As discussed in Caneta (2006), there is no empirical evidence to suggest that high-efficiency furnaces have different survival probabilities than standard efficiency furnaces. Moreover, engineering considerations suggest that, if anything, the greater complexity of high efficiency furnaces should mean a shorter lifetime on average. For these reasons, we expect the effect of subsidies on longevity to be negligible; we assume it to be zero in the empirical section of the paper below.

\subsection{An empiricall model of furnace replacement}

Given its relatively short duration, the EEH program provides a snapshot of household behavior within a very limited period, as shown by the interval $\left[t_{1}, t_{2}\right]$ in Figure 4 . Under the rules of the program, each household could claim only one grant. While it is technically possible that a household replaced its furnace more than once during this period, this possibility seems highly unlikely, since the median furnace lifespan in Canada is 18 years (Caneta 2006, p.18). Therefore we assume that each household replaced its furnace at most once during this period and we model household behavior during the program as a static choice between replacing the furnace or not, conditional upon the age of the existing furnace and other exogenous variables. The change in subsidy levels over the four-year interval of the data provides one dimension of variation in the net capital cost across observations in what is otherwise a static choice for the household within this interval; the other dimension of variation is provided by differences in 
subsidies among provinces. We return to the dynamics of the lifetime furnace replacement plan later, when we simulate the effect on household choice of removing subsidies.

We assume that, within the four-year timeframe of the EEH program, each household faces seven mutually exclusive furnace alternatives, indexed by $i=1, \ldots, 7$. The choice are: (1) no purchase, i.e. retain the original equipment (called the null alternative), (2) purchase an extra low efficiency furnace $(\text { AFUE }<90)^{17}$, (3) purchase a low efficiency furnace $(90 \leq \text { AFUE } \leq 91)^{18}$, (4) purchase a medium efficiency furnace (AFUE $\geq 92$ without a brushless DC fan motor) ${ }^{19}$, (5) purchase a high efficiency furnace ( $92 \leq$ AFUE $\leq 93$ with a brushless DC fan motor), (6) purchase an extra high efficiency furnace (AFUE $=94$ with a brushless DC fan motor), (7) purchase an ultra high efficiency furnace (AFUE $\geq 95$ with a brushless DC fan motor). Our choice of disaggregation of furnace alternatives is guided by the federal and provincial program designs, which distinguish between furnace categories in the same manner as we do here.

The utility of household $n$ conditional on purchasing alternative $i$ at time $t$ is given by $U_{\text {int }}$. As is standard, we adopt a random utility model, where utility is decomposed into observed $\left(V_{\text {int }}\right)$ and unobserved $\left(\varepsilon_{\text {int }}\right)$ components:

$U_{i n t}=V_{i n t}+\varepsilon_{i n t}$

The theoretical model indicates that utility is a function of furnace characteristics (including the capital cost of the furnace net of subsidies, and the efficiency of the furnace), geographic characteristics (including the price of energy and the climate), as well as house and household characteristics (including the size and shape of the house and effectiveness of the thermal envelope, the indoor temperature set-point, the age of the existing furnace, and household income). Unfortunately, our data set does not contain information on all of these potential determinants of household utility, precluding us from including all of these factors in $V_{\text {int }}$. Fortunately, the nature of the EEH program allows us to use fixed effects at the furnaceyear level to control for a number of these unobserved influences, and to use an operating cost

\footnotetext{
${ }^{17}$ Prior to December 31, 2009, federal regulation required all natural gas furnaces sold in Canada to have AFUE of 78 or higher. Effective on that date, the regulation was increased to a minimum AFUE of 90, while Manitoba enacted a provincial regulation requiring minimum AFUE of 92. Nonetheless, sales of furnaces with AFUE below 90 continued after that date, as vendors were permitted to sell off existing inventory..

${ }^{18}$ Historically, furnaces with AFUE of 90 and higher have been referred to as high efficiency. However, with the change in regulation at the end of 2009 (see previous note), AFUE of 90 and 91 in effect became the new low efficiency. With this in mind, we have developed our own nomenclature to distinguish the different levels of efficiency in the dataset. Note that AFUE is expressed as a whole number percentage in the data.

${ }^{19}$ Also referred to as an electronically commutated motor (ECM), the brushless DC fan motor uses significantly less electricity than a conventional motor, especially for households which run the fan continuously.
} 
variable that subsumes a number of these factors. For the observed component of utility, we adopt the specification:

$V_{\text {int }}=\alpha \cdot$ provincegrant $_{\text {int }}+\beta \cdot$ opcost $_{\text {int }}+\delta_{i t}$

where provincegrant $t_{i n t}$ is the dollar value of the provincial component of the subsidy for the furnace, opcost ${ }_{i n t}$ is the dollar value of the annual operating cost for the furnace, and $\alpha$ and $\beta$ are coefficients that capture the sensitivity of furnace choice to changes in grant value and operating cost. Finally, $\delta_{i t}$ is a fixed effect at the furnace-time level. We include the provincial grant amount as an independent variable, rather than the total federal plus provincial grant, because the furnace-year fixed effects absorb any changes in the federal grant amounts as well as the 2009 Home Renovation Tax Credit. Thus identification of furnace price sensitivity is based on differences in provincial grants over time.

The EEH dataset provides a simulated value of the annual operating cost of the original (pre-retrofit) furnace. This value is generated by building simulation software that takes into account the efficiency of the original furnace, as well as the large number of house characteristics in the EEH database (as described above), climate, and energy price. Taking this value as our baseline, we then estimate the operating cost of any alternative $i$ by scaling the original operating cost by the adjustment factor $A F U E_{\text {original }} / A F U E_{i}$ :

opcost $_{\text {in }}=$ opcost $_{\text {original, } n} \cdot A F U E_{\text {original }} / A F U E_{i}$.

Appendix 2 elaborates on our calculation of AFUE. Note that this measure of operating cost reflects the relevant exogenous characteristics of the house as well as energy prices and climate, which is why these variables do not enter our specification (7) explicitly.

One shortcoming of our calculation of operating cost is that it is based upon a common temperature set-point of $21^{\circ} \mathrm{C}$ for all households and all efficiency choices. ${ }^{20}$ Fortunately, any bias resulting from this assumption is likely to be small. First, evidence suggests there is very little variation in thermostat set-points in Canada. For example, the Canadian Mortgage and Housing Corporation reports that most households in a random survey maintained set-points between 20 and $21{ }^{\circ} \mathrm{C} .{ }^{21}$ Second, existing studies suggest a very small response of temperature set-point to changes in equipment efficiency (Greening, Greene, \& Difiglio, 2000). Third, as part of the energy efficiency audits in the EEH program, homeowners were provided with

\footnotetext{
${ }^{20}$ The building simulation software employs this assumption and we maintain it with our linear scaling.

${ }^{21}$ See http://www.cmhc-schl.gc.ca/en/co/grho/grho_002.cfm.
} 
comparisons of operating costs under current and alternative furnaces based on the same assumption regarding temperature set-point. Therefore, it is likely that many households perceived these cost measures to be the correct ones, and made decisions based on these values.

Furnace capital costs are not explicitly included in (7) but are instead absorbed in the furnace-time fixed effect, $\delta_{i t}$. This specification allows for arbitrary changes in furnace prices by type over time, which is likely important. For example, during our time frame, furnaces of the highest efficiency level experienced substantial gains in market share at the expense of lowefficiency furnaces. The furnace-time fixed effect also includes any non-price characteristics of furnaces that change over time, including general perceptions and marketing efforts.

In the programs under study, the grant which a household received was determined based on information collected at a post-retrofit audit. However, grant levels changed over time, creating the possibility that some households may have made their retrofit decisions based on the grant in place at the time of the decision only to see it changed by the time of the post-retrofit audit. Since we do not know precisely when each household made its retrofit decision, we assume that the household decision is based on grant levels in effect at the time of the pre-retrofit audit. $^{22}$

As discussed previously, the age of the existing furnace is also an important determinant of the effect of the subsidy policy. Unfortunately, our dataset does not include the age of the existing furnace. Therefore, we must consider this as an element of the unobserved component of utility, $\varepsilon_{i n}$. We expect that this approach will lead to correlation among the unobserved components for households that are at or close to $R^{1}$ when the subsidy is made available (old furnace, e.g. panels $b$ and $c$ in Figure 4). Such households experience above average utility for alternatives 2, 3, 4, 5, 6 and 7 (the replacement alternatives) ceteris paribus and below average utility for alternative 1 (the null alternative). Conversely, households with relatively young furnaces when the subsidy is made available (panel $d$ in Figure 4) experience below average utility for the replacement alternatives ceteris paribus and above average utility for the null alternative.

This type of correlation between the unobserved components of utility, in which alternatives can be grouped into pre-defined sets, points towards estimation with a nested model

\footnotetext{
${ }^{22}$ We also test the sensitivity of the results by using realized grants at the time of the post-retrofit audit. This has little effect on our results.
} 
Train (2009). Our nested model groups all replacement alternatives in one nest and the null alternative in a separate nest. Let these two nests be indexed by $k \in\{1,2\}$. The subset of furnaces in nest $k$ is denoted $F_{k}$. In particular, we assume $F_{1}$ contains the null alternative $(i=1)$ and $F_{2}$ contains the replacement alternatives (i.e. $i=2, \ldots, 7$ ). We assume the unobserved utility components $\varepsilon_{\text {in }}$ are jointly distributed as a generalized extreme value, which yields the nested logit model.

Formally, the probability of choosing furnace alternative $i$ is:

$P_{i n}=\frac{e^{V_{i n} / \lambda_{k}}\left(\sum_{j \in F_{k}} e^{V_{j n} / \lambda_{k}}\right)^{\lambda_{k}-1}}{\sum_{l=1}^{2}\left(\sum_{j \in F_{l}} e^{V_{j n} / \lambda_{l}}\right)^{\lambda_{l}}}$

where $\lambda_{k}$ is a measure of correlation in unobserved utility amongst the alternatives in nest $k$; high values of $\lambda_{k}$ imply less correlation. Note that, because $F_{1}$ consists of a single element, it follows that $\lambda_{1}=1$. Thus

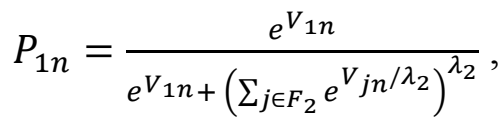

and

$P_{i n}=\frac{e^{V_{i n} / \lambda_{k}}}{\left(\sum_{j \in F_{2}} e^{V_{j n} / \lambda_{2}}\right)^{\left(1-\lambda_{2}\right)}\left(e^{V_{1 n}}+\left(\sum_{j \in F_{2}} e^{V_{j n} / \lambda_{2}}\right)^{\lambda_{2}}\right)}, \quad i=2, \ldots 7$.

\section{Results}

\subsection{Discrete choice model estimation}

Table 2 reports regression results for the discrete choice model described in the previous section. It turns out that the EEH dataset is a choice-based sample, and therefore standard exogenous sample maximum likelihood will produce biased estimates of the coefficients. To address this problem, we use weighted exogenous sample maximum likelihood (WESML), following Manski and Lerman (1977). We discuss the calculation of weights in Appendix 2.

We only report estimates for the coefficients on opcost and provincegrant in Table 2, since these variables are the main focus of the paper. We find the expected signs for the two main parameters of interest: increases in the operating cost of a furnace reduce utility, while increases in grants (i.e., reductions in up-front cost) increase utility. Further, both coefficients are estimated precisely. 
The ratio of these two coefficients indicates the willingness of homeowners to trade off increases in capital cost for reductions in operating cost. Assuming that the furnace is longlived, this ratio is equivalent to the implicit discount rate applied by the consumer in purchasing the asset. ${ }^{23}$ Using the results in the first column, we estimate that households employ a discount rate of 61 percent in making natural gas furnace purchases. ${ }^{24}$ Similar high discount rates are observed in other studies of energy efficient technology investments; for example Gillingham et al. (2009) and Train (1985) report evidence of discount rates of 25 to 100 percent in previous studies of energy efficiency technology choice.

We also report the "dissimilarity parameter" $\lambda_{2}$ for the second nest, which takes on a value of 0.37 . This is between 0 and 1 , which indicates positive correlation among the replacement alternatives - as expected. Values between 0 and 1 are also consistent with utility maximization (Train 2009), which is reassuring. The implication is that when the price of a furnace is increased, homeowners will be pre-disposed to switch to another furnace rather than the null alternative.

In Table 2, we re-estimate the nested logit model for two mutually exclusive subsets of the data. We split the data into two segments based on the date of the initial home audit. In the first column of the table, we estimate the nested logit model for all observations for which the initial home audit was conducted in years 2007 and 2008, while in the second column, we estimate the same model for all observations conducted in years 2009 and later. In 2009, the federal government supplemented the EEH program with the Home Renovation Tax Credit. By including furnace-time fixed effects, we aim to absorb the effect of this supplementary program, but because the specific value of the HRTC varies by household, our fixed effect strategy may not perfectly absorb the effect of the HRTC. Estimating the model over different time subsets provides a useful check on our previous results. As shown in the table, coefficient estimates are stable across the different sub-samples, providing additional confidence in our fixed effects strategy.

\footnotetext{
${ }^{23}$ Formally, if the life of the furnace is $q$ and the discount rate is $r$, the ratio of coefficients is equal to: $\frac{\alpha}{\beta}=$ $-\frac{r}{\left(1-(1+r)^{q}\right)}$ (Train 1985). Assuming a furnace life of $q=15$, the approximation $\frac{\alpha}{\beta}=-r$ is valid to two decimal places with coefficients as reported. The discount rate is calculated assuming constant energy prices and under the assumption that the furnace is scrapped by the consumer at the end of its life.

${ }^{24} \mathrm{We}$ use the delta method to estimate the standard error of the discount rate.
} 
The above models are estimated without using income as a covariate. We prefer this approach, since the administrative data set is missing a full postal code identifier for about one third of the total number of observations, and using income as a covariate requires dropping these observations. However, we re-estimate the models using income interacted with furnace dummy variables on the subset of households with geographic indicators, and we find little change in results. Further, we find that higher income households are more likely to choose the null (no furnace retrofit) alternative, but conditional on retrofitting, are more likely to choose the highest efficiency models. The coefficients on income are statistically significant at the $5 \%$ level in nearly all cases.

\subsection{Incidence of retrofit grants}

In addition to estimating the effect of retrofit grants on furnace choices, our second goal is to estimate the distributional incidence of the program. In order to do this, we use the program data to find the total number and value of grants received by geographical area. We merge this data with census data, and use the results to determine the incidence of the combined federal and provincial programs according to census demographic characteristics. ${ }^{25}$ The smallest census aggregation with publicly available income data is the Census Dissemination Area (CDA), and so results in this section are at this level of disaggregation.

The distribution of furnace grants by average income is shown in Figure 5 and Figure 6. Figure 5 shows the mean value of natural gas furnace retrofit grants by income, during the fouryear period in which we have data. We generate the figure by dividing the total value of retrofit grants in each CDA by the total number of households in the CDA. A clear pattern emerges, particularly at low levels of income. In Census Dissemination Areas with low levels of average individual income, very few or no grants are received by households. The number of grants received by households increases linearly up to an average income of about $\$ 55,000$, at which point about 5 percent of households obtain natural gas furnace retrofit grants, with a mean value of about $\$ 70$. Beyond an income of $\$ 55,000$, the proportion of households receiving grants is relatively unchanged, as is the value of grants received by households.

Figure 6 shows the mean value of grants received per owner-occupied household, according to the income in the Census Dissemination Area. The figure shows that contingent on

\footnotetext{
${ }^{25}$ We exclude the HRTC from this analysis.
} 
home ownership, the mean value of natural gas furnace grants is relatively constant at different income levels. Therefore the regressive pattern observed in Figure 5 is a result of differences in the proportion of owner-occupied dwellings at different levels of income, rather than due to differences in the average grant per homeowner that participates in the program receive at different levels of income.

Overall, the results reveal an interesting pattern. Most furnace grants are obtained by households in census areas with average incomes in excess of $\$ 50,000$, and census districts in regions with low income receive much smaller number and value of grants. On this metric, the program appears regressive. Interestingly, the value and number of grants obtained declines slightly at higher levels of income, such that the largest recipients of the program appear to be in geographic areas with incomes between $\$ 50,000$ and $\$ 150,000$ (middle income areas).

\section{Counterfactual simulations}

We can use the regression results to estimate the change in relative furnace market shares due to the grants, and to calculate the energy and greenhouse gas savings due to the program. We first calculate predicted probabilities of each household $n$ in the sample choosing furnace alternative $i, \hat{P}_{n i}$, based on equation (9), using the estimated coefficients. We then repeat this calculation and calculate predicted probabilities of furnace choice when grants are set to zero, $\hat{P}_{n i}^{*}$. We generate a separate set of predicted probabilities corresponding to the following counterfactuals: (i) eliminating provincial grants, (ii) eliminating combined provincial and federal grants, (iii) eliminating provincial and federal grants and the Home Retrofit Tax Credit. ${ }^{26}$

Table 3 reports estimates of predicted market shares for each of the scenarios identified above. Amongst the subset of all households with natural gas forced air furnace enrolled in the EEH program, 54 percent chose the most efficient new furnace 95 percent AFUE with DC motor), 24 percent did not purchase a new furnace, 13 percent chose the second most efficient furnace (94 percent AFUE with DC motor), and the remainder purchased a less efficient furnace (column A). Removing retrofit grants (provincial and federal), which encourage purchase of the most efficient furnaces, causes some households to switch furnace alternatives or to avoid furnace purchase (columns B and C). Removing the HRTC, which provides subsidies on all

\footnotetext{
${ }^{26}$ In (ii) and (iii), the provincegrant variable is set at negative values, corresponding with the federal grant and federal grant + HRTC respectively.
} 
furnaces (with some conditions), causes some households not to purchase a new furnace. With all subsidies removed (column D), we predict that 59 percent of program participants would not have purchased a new furnace during the program timeframe, and that only 21 percent would have purchased the most efficient new furnace.

However, we must be very careful how we interpret the figures for the null alternative. No furnace lasts forever, and therefore no household can go forever without purchasing a new furnace. Instead, the share of households associated with the null in Table 3 are those which would not have purchased a furnace within the timeframe of the programs under study, i.e. April 1, 2007 - March 31, 2011. Thus column A indicates that 24\% of observations in the sample are of the type illustrated in Figure 4(d) - households which were not affected by the subsidy program and therefore followed their original replacement schedule. Column D indicates that $59 \%$ of the sample would not have purchased a furnace during the same timeframe in the absence of subsidies. This group includes the original 24\% from Column A plus an additional $35 \%$ of observations of the type illustrated in panels (b) and (c) of Figure 4 - households whose original replacement dates were outside the program interval but who were induced to move their date of replacement forward in order to claim a subsidy.

We can use the estimated model to predict which furnace choices these households would have made, in the absence of subsidies, when their replacement dates arrived. We show this result in Column E; i.e. the long-run allocation of households among the replacement alternatives in the absence of all subsidies. In particular, we have allocated the $59 \%$ of households associated with the null alternative in Column D (during the April 1, 2007 - March 31, 2011 timeframe) among the replacement alternatives. ${ }^{27}$ We observe that $50 \%$ of the sample households would have chosen the most efficient furnace alternative over the course of time, without any inducement from subsidies.

Column F shows the long-run allocation of households among the replacement alternatives with the actual program of subsidies offered during the April 1, 2007 - March 31, 2011 timeframe, followed by no subsidies thereafter. We observe that $72 \%$ of the sample households choose the most efficient furnace alternative in this scenario involving a temporary subsidy program.

\footnotetext{
${ }^{27}$ We have moved the selections of AFUE $<90$ to the next higher category, as this alternative was phased out at the end of 2009. See footnote 18.
} 
Next we generate an estimate of free-ridership on the subsidy programs. As discussed above, a free-rider is a household which replaces its furnace with the same model it would have chosen in the absence of subsidies. Using $N$ to denote the total number of households in the sample, we begin by observing that the $0.21 \mathrm{~N}$ households indicated in cell D7 of Table 3 are free-riding by definition - they would have installed the highest efficiency furnace during the program timeframe even without a subsidy.

It is tempting to draw the same conclusion for the share of households indicated in cells D6, D5, etc. of Table 3. However, such conclusions would be incorrect, since the offer of subsidies would motivate some of these households to move up to a higher level of efficiency. Instead, we must employ a multi-step procedure in which we generate counterfactuals in which subsidies are turned on for some alternatives but left off for others.

First, we consider a scenario where subsidies are turned on (provincial, federal, and the HRTC) for the highest efficiency furnace (alternative 7) but turned off for the others. Since the estimated subsidy coefficient is positive and the estimated $\lambda_{2}<1$ (Table 2), it follows from ( $\left(9^{\prime}\right)$ and $\left(9^{\prime \prime}\right)$ that turning on subsidies for alternative 7 and leaving them off for the other alternatives will increase the market share for alternative 7 and decrease it for alternatives $1-6$. The households left in alternative 6 in this approach are free-riders (not shown in the figure) households that are not motivated to change their selection by the presence of subsidies for more efficient alternatives.

In contrast, not all of the households left in alternatives $1-5$ in this scenario are free riders, since some of these households would likely be motivated to move up to alternative 6 if a subsidy were offered. Therefore, we must now consider a scenario in which subsidies are turned on for alternatives 6 and 7 but turned off for the others. This approach increases the estimated market share for alternatives 6 and 7 and decreases it for alternatives $1-5$ (from $\left(9^{\prime}\right)$ and $\left(9^{\prime \prime}\right)$ ). It follows that the remaining households in alternative 5 are free-riders. We then continue to assess alternatives 4,3 , in the same manner.

We conduct the preceding calculation for each of the grants considered in the analysis: federal, provincial, and the HRTC. The results of these calculations suggest that approximately 72 percent of the federal subsidy recipients are free-riders, 64 percent of the provincial subsidy recipients are free-riders, and 86 percent of the HRTC grant recipients are free-riders. ${ }^{28}$

\footnotetext{
${ }^{28}$ These calculations are for each individual program, rather than for all programs considered together.
} 
Next we compare the aggregate fuel consumption of households in the sample when subsidies are present to the counterfactual case when subsidies are removed. Taking the difference between the two measures yields an estimate of the energy and greenhouse gas savings attributable to the program. We estimate fuel expenditure savings, $S$, as

$S=\sum_{n i}\left(\hat{P}_{n i} o_{0 p} \operatorname{cost}_{n i}-\hat{P}_{n i}^{*}\right.$ opcost $\left.t_{n i}\right)$,

where opcost $n$ is natural gas expenditures for household $n$ conditional on choosing furnace $i$. We conduct the calculation using both the short run probabilities (with values for $\hat{P}_{n i}$ corresponding to column A of Table 3 and values for $\widehat{P}_{n i}^{*}$ corresponding to column D) and the long-run replacement choices of households (with values corresponding to columns E and F of Table 3).

To estimate natural gas savings in energy units, we divide opcost $t_{n i}$ by the natural gas price faced by each consumer at the time of retrofit (obtained from the EEH dataset), and recalculate (8). We then estimate greenhouse gas savings attributable to the program by dividing by a coefficient that captures the emission intensity of natural gas fuel. ${ }^{29}$ In order to estimate energy and greenhouse gas savings attributable to the program, we assume a furnace life of 15 years, and we do not discount future savings in greenhouse gases or energy.

Table 5 presents the results of our calculations for greenhouse gases. The short-run calculations suggest that the program has saved about $0.2 \mathrm{Mt} \mathrm{CO}_{2}$ per year on average, by encouraging homeowners to select more efficient furnaces. Assuming a furnace life of 15 years, this suggests a total emission saving due to the program of around $3 \mathrm{Mt}$ of $\mathrm{CO}_{2}$. However, as we discuss above, this is likely to be an overestimate to the extent that the households that selected the null furnace option would eventually have to replace their furnace. By accounting for long run furnace replacements, we estimate that the program only reduces emissions by about $0.03 \mathrm{Mt}$ $\mathrm{CO}_{2}$ per year on average, for a total reduction over 15 years of about $0.5 \mathrm{Mt} \mathrm{CO}_{2}$.

We can now estimate the cost effectiveness of the program by comparing emission savings to total program cost in Table 5. Total program expenditures (for natural gas furnace replacement) for households covered by our data are \$431 million when the value of the HRTC is included, and \$287 million when the value of the HRTC is excluded. We find a total cost effectiveness of the program of $\$ 100 / \mathrm{t} \mathrm{CO}_{2}$ reduced when considering only non-HRTC expenditures and adopting the short-run furnace replacement probabilities. By including the

\footnotetext{
${ }^{29}$ We adopt Environment Canada's natural gas emissions coefficient of $1900 \mathrm{~g} \mathrm{CO}_{2} \mathrm{e} / \mathrm{m}^{3}$ of natural gas.
} 
costs of the HRTC and focusing on the long-run furnace replacement probabilities, the cost effectiveness of the program is significantly worsened to over $\$ 800 / \mathrm{t} \mathrm{CO}_{2}$.

These values are very high compared to other policy options government could have used to obtain emission reductions. For example, domestic offset credits typically trade at less than $\$ 30 / \mathrm{t} \mathrm{CO}_{2}$, EU emission trading credits trade at between $\$ 5$ and $\$ 30 / \mathrm{t} \mathrm{CO}_{2}$, and Clean Development Mechanism credits trade at around the same value. ${ }^{30}$

\section{Conclusion}

A number of prominent studies have found evidence of an "energy efficiency gap," whereby consumers invest less in energy efficient products than would be expected if they were aiming to minimize energy service costs. Partly in response to this literature, governments have adopted information and incentive programs to encourage uptake of energy efficient technologies and practices. This paper is an analysis of federal and provincial retrofit programs in Canada, between April 1, 2007 and March 31, 2011. We use the significant spatial and temporal heterogeneity in grants provided for adoption of natural gas forced air furnaces to identify the sensitivity of furnace choice to grant level. We then simulate a counterfactual scenario where grants are eliminated in order to find the effect of the subsidy programs compared to a no-subsidy counterfactual. Comparing these two scenarios allows us to estimate the effect of the program on furnace market shares, energy consumption, and greenhouse gas emissions.

Our findings suggest that a significant portion of the furnace grants provided during the sample period were not additional; that is, they were obtained by households that would have purchased energy efficient furnaces even without the grants. In addition, we find that energy and greenhouse gas savings due to the program were limited. This is in part because there are only small differences in energy efficiency between high-efficiency and "low"-efficiency natural gas furnaces. However, it is also because of the additionality problem described above, which magnifies the cost of the program and worsens cost-effectiveness. We also examine the incidence of the program, and find that most of the benefits from the program accrue to relatively wealthy households.

\footnotetext{
${ }^{30}$ See www.pointcarbon.com.
} 
Overall, our results suggest that this type of residential energy efficiency retrofit program is likely not the most effective way for governments to encourage adoption of high-efficiency technologies and to reduce greenhouse gas emissions. Instead, government should explore other policy options that are likely to deliver more greenhouse gas abatement at a lower cost.

\section{Bibliography}

Allcott, H., \& Greenstone, M. (2012). Is there and energy efficiency gap? Journal of Economic Perspectives, 26(1), 3-28.

Cameron, T. (1985). A nested logit model of energy conservation activity by owners of existing single family dwellings. The Review of Economics and Statistics, 205-211.

Caneta Research Inc. (2006). Update of market and economic analysis of residential gas furnace efficiency levels in Canada. Office of Energy Efficiency, Natural Resources Canada.

Cropper, M., \& Freeman, A. M. (1991). Environmental Health Effects. In e. John B. Braden and Charles D. Kolstad, Measuring the Demand for Environmental Quality (pp. 165-211). North-Holland.

Gillingham, K., \& Palmer, K. (2014). Bridging the energy efficiency gap: Policy insights from economics theory and empirical evidence. Review of Environmental Economics and Policy, 1-21.

Gillingham, K., Newell, R., \& Palmer, K. (2009). Energy efficiency economics and policy. Annual review of resource economics, 1, 597-619.

Greening, L., Greene, D., \& Difiglio, C. (2000). Energy efficiency and consumption - the rebound effect - a survey. Energy Policy, 28(6), 389-401.

Grosche, P., \& Vance, C. (2009). Willingness-to-pay for energy conservation and free-ridership on subsidization - Evidence from Germany. The Energy Journal, 141-160.

Grosche, P., Schmidt, C., \& Vance, C. (2009). Identifying free-riding in energy-conservation programs using revealed preference data. Ruhr Economic Papers, 1-23.

Gusdorf, J., Swinton, M., Simpson, C., Entchev, E., Hayden, S., \& Castellan, B. (2003). Final report on the effect of ECM furnace motors on electricity and gas use: Results from the CCHT research facility and projections. Buildings Group - Energy Sector, CANMET Energy Technology Centre, Department of Natural Resources Canada.

Hartman, R. (1988). Self-selection bias in the evolution of voluntary energy conservation programs. The Review of Economics and Statistics, 448-458.

Hausman, J. (1979). Individual discount rates and the purchase of energy using durables. The Bell Journal of Economics, 10(1), 33-54. 
Manski, C., \& Lerman, S. (1977). The estimation of choice probabilities from choice based samples. Econometrica, 45(8), 1977-1988.

McKinsey\&Company. (2009). Pathways to a low carbon economy.

Revelt, D., \& Train, K. (1998). Mixed logit with repeated choices: Households' choices of appliance efficiency level. The Review of Economics and Statistics, 647-657.

Train, K. (1985). Discount rates in consumers' energy-related decisions: A review of the literature. Energy, 10(12), 1243-1253.

Train, K. (2009). Discrete choice methods with simulation. Cambridge University Press.

Train, K., \& Atherton, T. (1995). Rebates, Loans, and Customers' Choice of Appliance Efficiency Level: Combining Stated- and Revealed-Preference Data. The Energy Journal, $55-70$. 


\section{Figures}

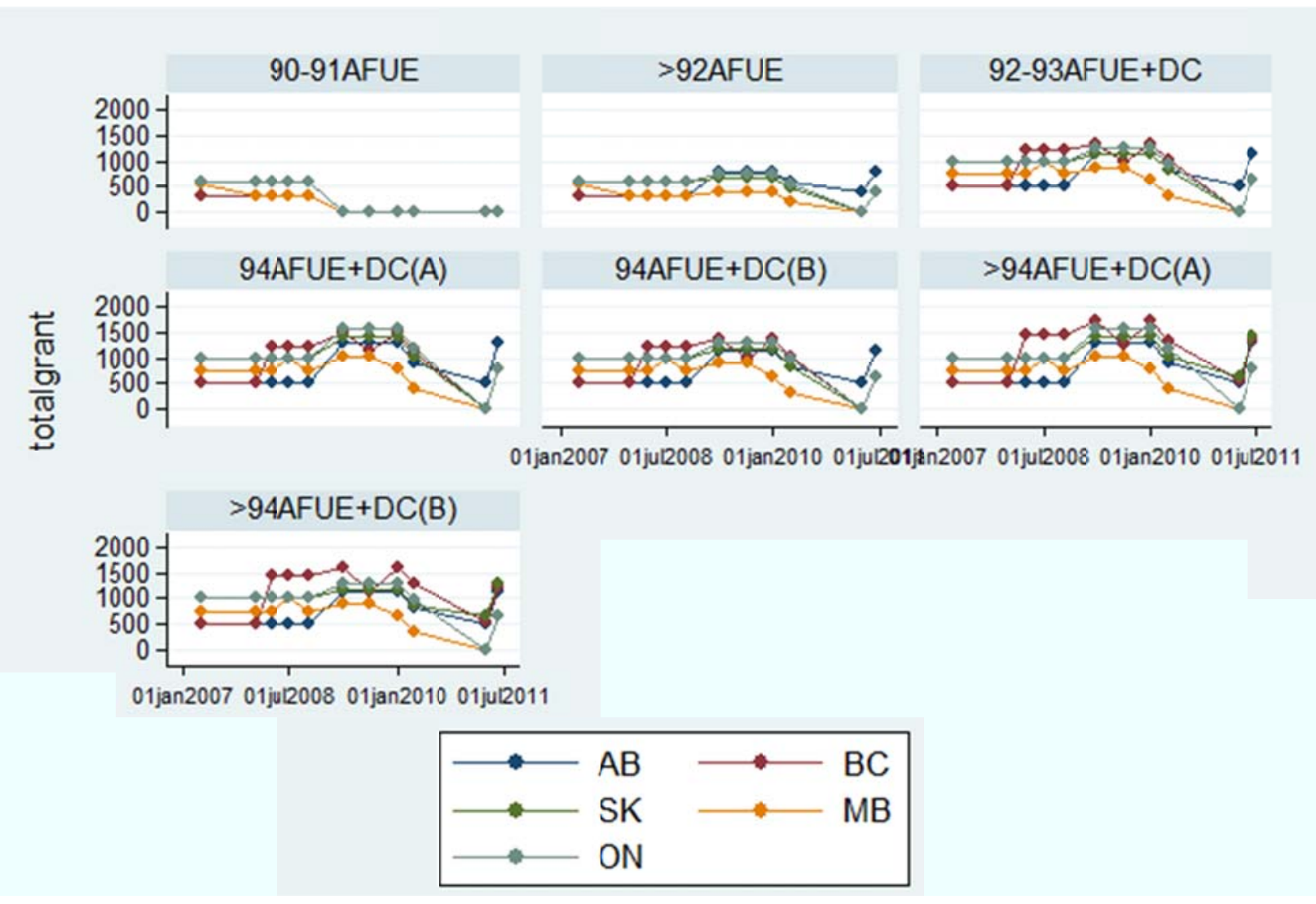

Figure 1: Variation in furnace subsidies by time and province. Grant levels differ by furnace AFUE rating. An (A) indicates that the household did not previously have a condensing (high-efficiency) furnace, and a (B) indicates that the new furnace replaces a condensing furnace. Grant levels in the figure are the sum of federal and provincial grants. There is some sub-provincial variation in grants, which is not shown in this figure to reduce clutter. Additionally, although some grants are based on the date of the postretrofit audit, in the figure, all grants are classified by date of pre-retrofit audit for simplicity. 


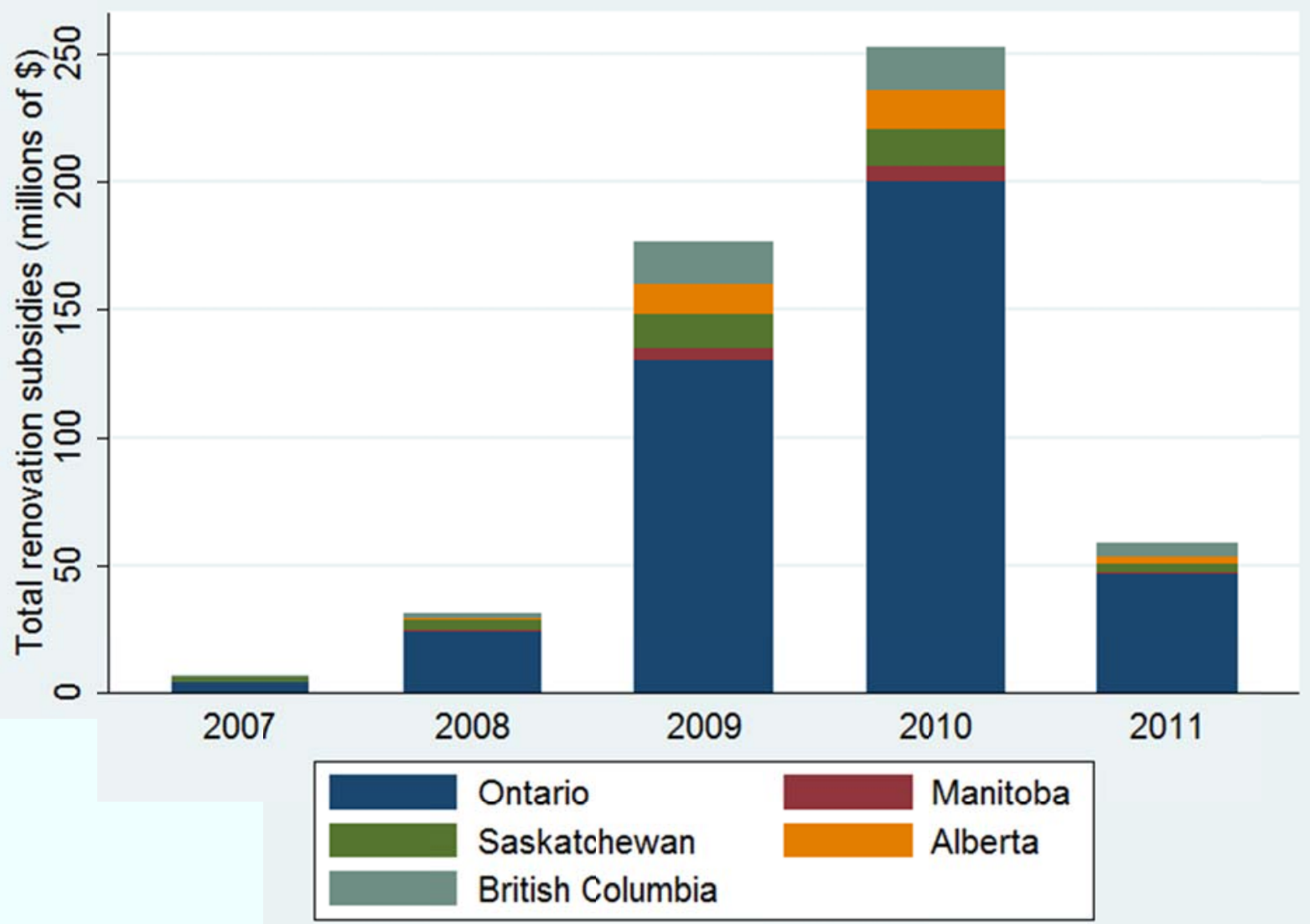

Figure 2: Total natural gas forced air grant amount by year and province. Calculations are made by multiplying grants by observed frequency of furnace choices. Grants include the federal EEH program and cooperating provincial and utility programs as well as the federal Home Renovation Tax Credit (estimated as described in Appendix). 


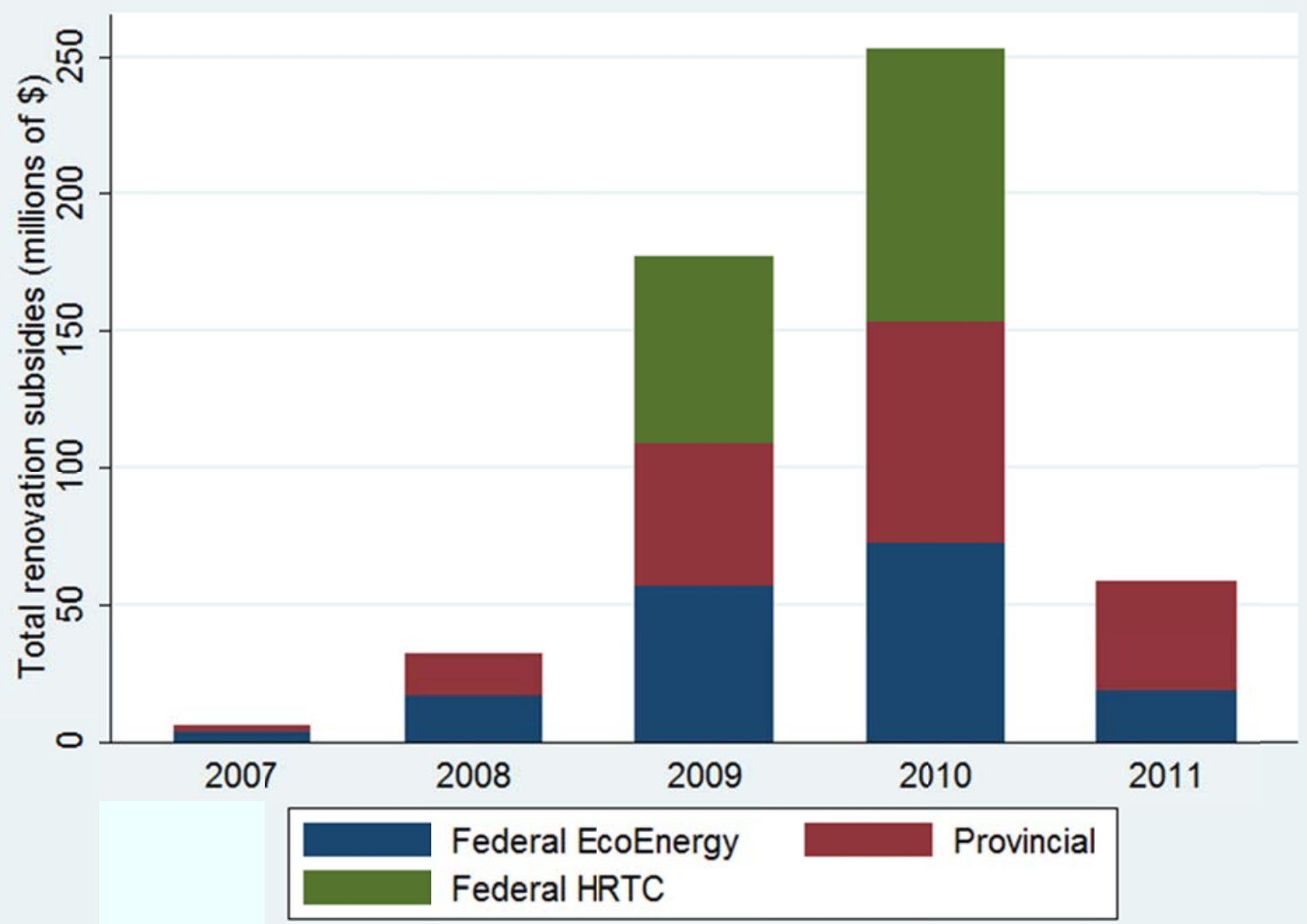

Figure 3: Total natural gas forced air grant amount by year and source of grant. Calculations are made by multiplying grant amount by observed frequency of furnace choices. 
Figure 4: Furnace replacement theoretical model. Vertical axis is furnace efficiency. Horizontal axis is time.
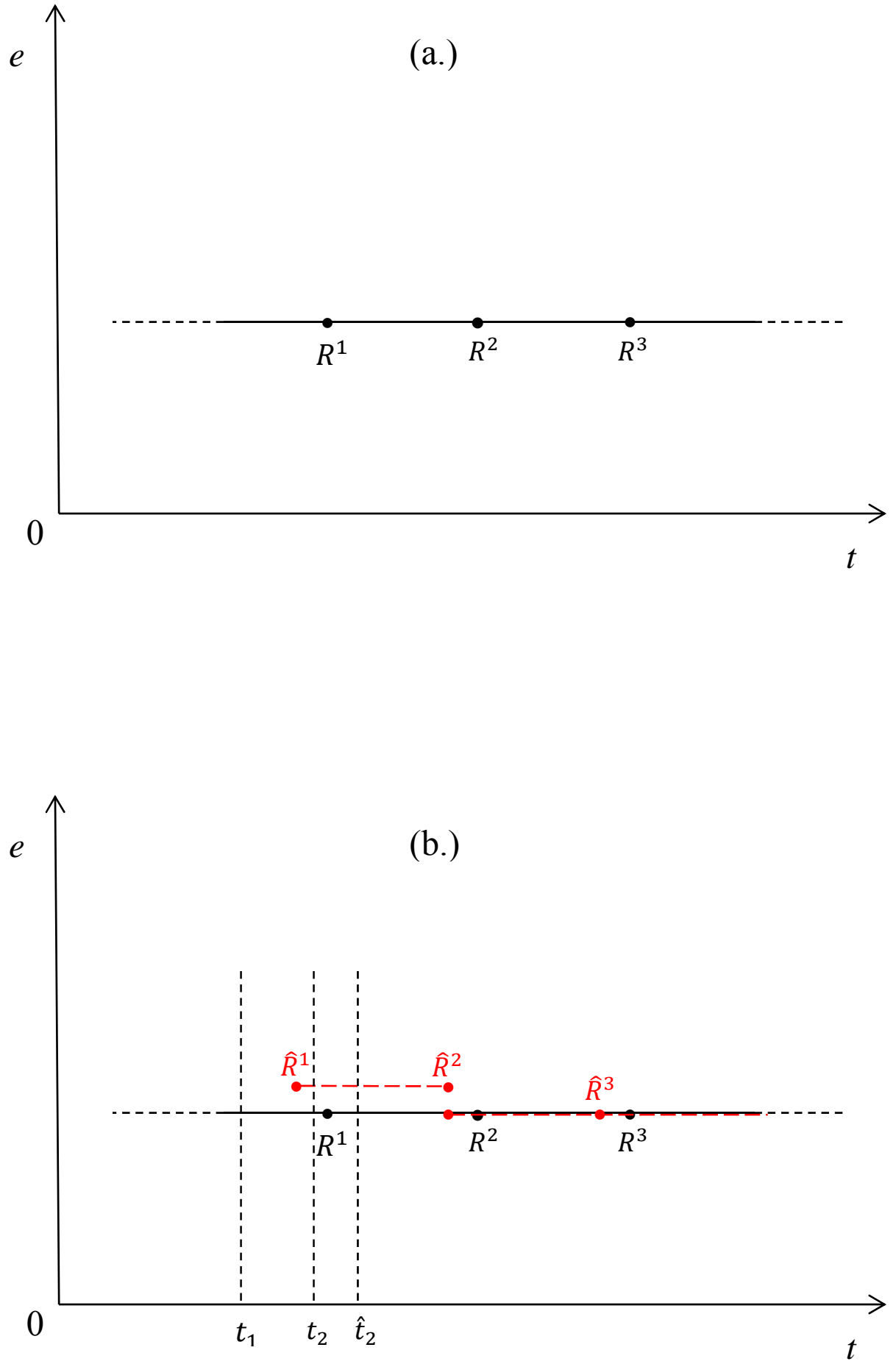

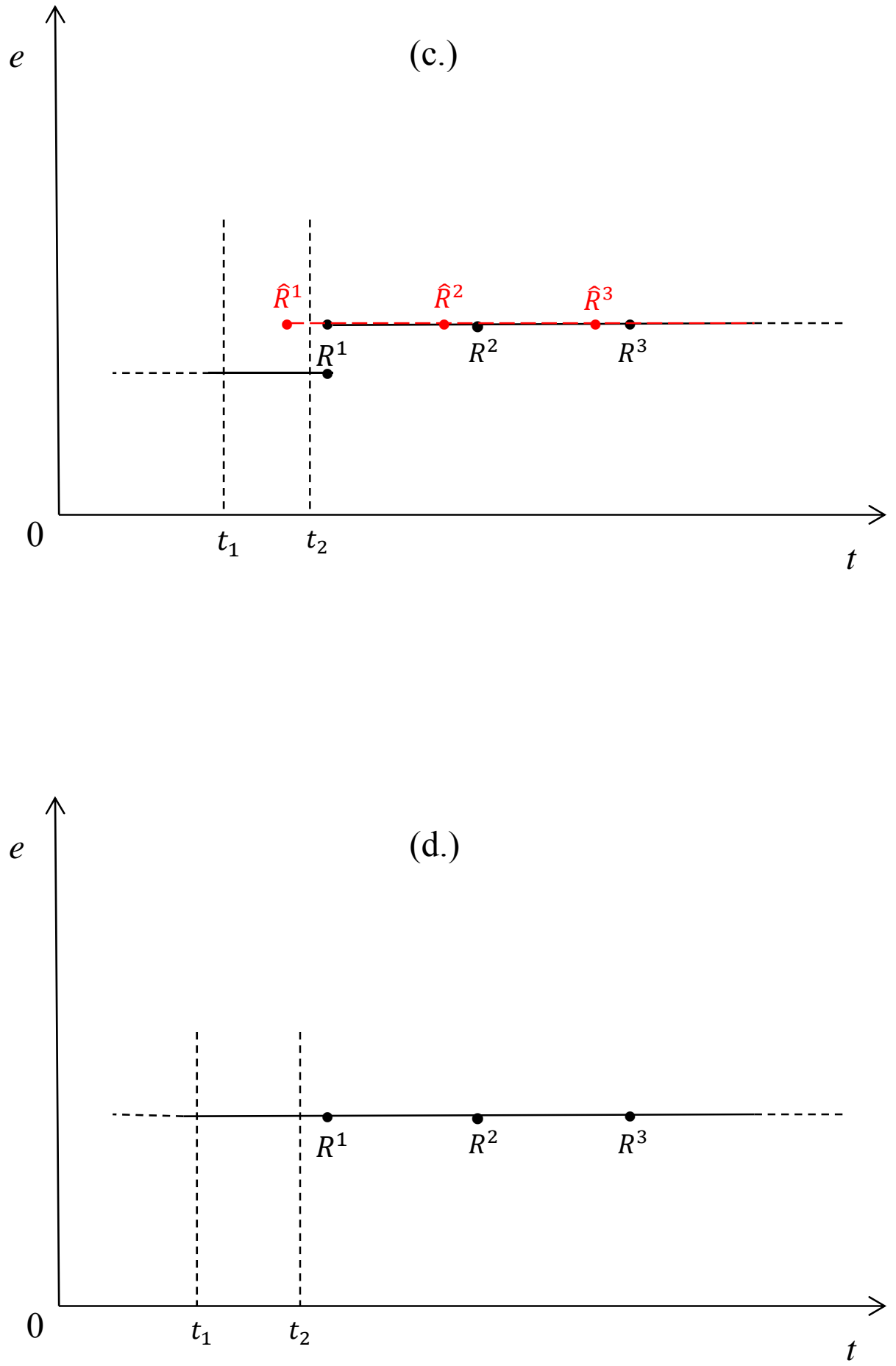


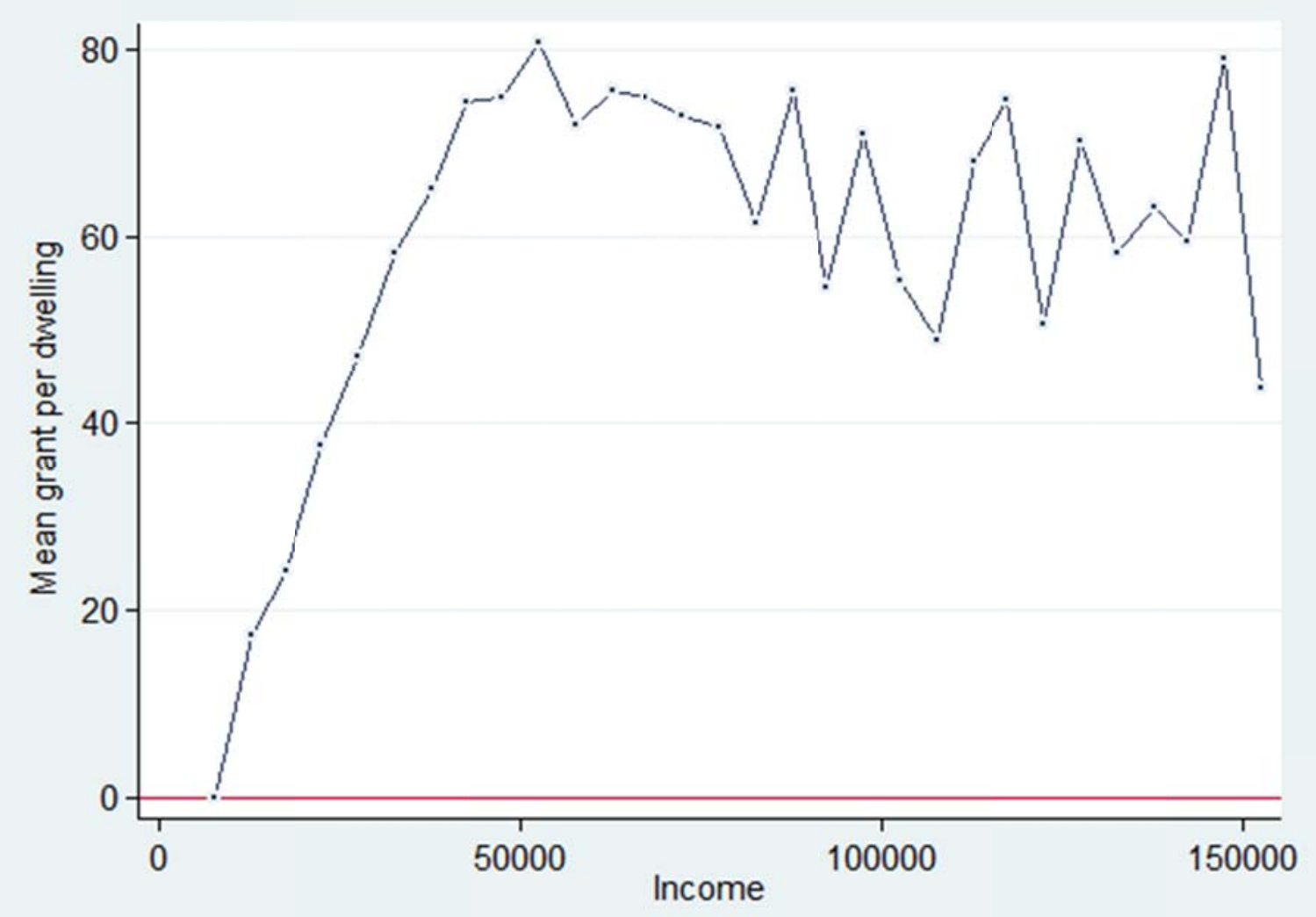

Figure 5: Mean total value of natural gas furnace grants per private dwelling by income (\$C). Bins are of width $\$ 5,000$ except the top bin, which includes all geographic areas with average income greater than $\$ \mathbf{1 5 0 , 0 0 0}$. The income measure used is the average income from all sources for individuals $\mathbf{1 5}$ years and older. 


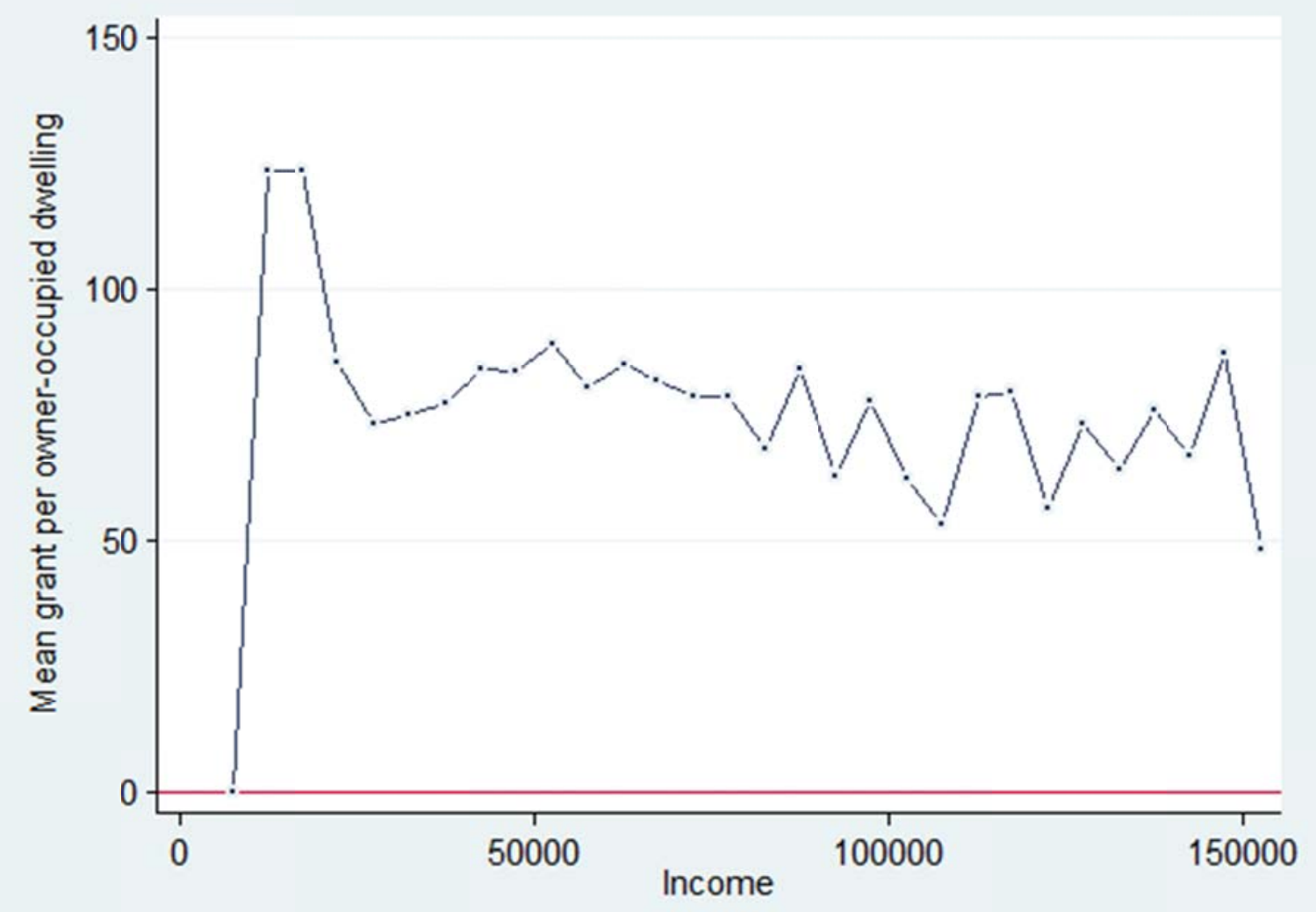

Figure 6: Mean total value of natural gas furnace grants per owner-occupied private dwelling by income (\$C). Bins are of width $\$ 5,000$ except the top bin, which includes all geographic areas with average income greater than $\$ 150,000$. The income measure used is the average income from all sources for individuals 15 years and greater. 


\section{Tables}

Table 1: Main summary statistics for the data

\begin{tabular}{clll}
\hline & $N$ & share & \\
\hline Province & 328,668 & 0.76 & \\
ON & 328,668 & 0.03 & \\
MB & 328,668 & 0.07 & \\
SK & 328,668 & 0.06 & \\
AB & 328,668 & 0.08 & 18,055 \\
BC & & & \\
& $N$ & mean & 792 \\
\hline Income & 252,688 & 39,093 & 702 \\
Annual gas cost (\$) & & & \\
Original furnace & 328,668 & 1886 & 4.97 \\
New furnace & 328,668 & 1668 & 6.00 \\
& & & \\
Efficiency (AFUE) & & & 325 \\
Original furnace & 328,668 & 79.99 & 339 \\
New furnace & 328,668 & 91.62 & 441 \\
Subsidies received (\$) & & & \\
Provincial & & & \\
Federal EEH & 328,668 & 395 & \\
Federal HRTC & 328,668 & 438 & \\
& 328,668 & & \\
\hline
\end{tabular}


Table 2: Discrete choice model output (WESML). Model includes furnace-time fixed effects. All models are nested logit as described in the text. N_total refers to the total number of observations (individuals times alternatives). N_cases refers to the number of individual households in the sample. $\mathrm{Il}$ is the log-likelihood. The discount rate is the ratio of opcost and provincegrant coefficients and the standard error of the discount rate is calculated using the delta method.

\begin{tabular}{llll}
\hline & $(1)$ & $(2)$ & $(3)$ \\
& All years & Pre-2009 & Post-2008 \\
\hline \multirow{2}{*}{ opcost } & & & \\
& $-0.00153^{* * *}$ & $-0.00271^{* * *}$ & $-0.00229^{* * *}$ \\
& $(0.0000277)$ & $(0.000107)$ & $(0.0000258)$ \\
provincegrant & & & \\
& $0.000937^{* * *}$ & $0.00134^{* * *}$ & $0.000929^{* * *}$ \\
\hline$\lambda$ & $(0.0000262)$ & $(0.0000750)$ & $(0.0000186)$ \\
\hline Discount rate & 0.382 & 0.836 & 0.343 \\
& $(0.030)$ & $(0.0861)$ & $(0.0075)$ \\
\hline N_total & $61.4 \%$ & $49.4 \%$ & $40.5 \%$ \\
\hline N_cases & $(2.1 \%)$ & $(3.3)$ & $(0.9 \%)$ \\
11 & 2300676 & 273168 & 2027508 \\
\hline
\end{tabular}

Standard errors in parentheses

${ }^{*} p<0.05,{ }^{* *} p<0.01,{ }^{* * *} p<0.001$

WESML: weighted exogenous sample maximum likelihood 
Table 3: Simulated market shares of natural gas forced air furnaces.

\begin{tabular}{|c|c|c|c|c|c|c|}
\hline Alternative & $\begin{array}{l}\text { With } \\
\text { all } \\
\text { grants }\end{array}$ & $\begin{array}{l}\text { Remove } \\
\text { prov } \\
\text { grants }\end{array}$ & $\begin{array}{l}\text { Remove } \\
\text { prov \& } \\
\text { fed } \\
\text { grants }\end{array}$ & $\begin{array}{l}\text { Remove } \\
\text { prov, } \\
\text { fed } \\
\text { grants } \\
\& \\
\text { HRTC }\end{array}$ & $\begin{array}{l}\text { Remove } \\
\text { prov, } \\
\text { fed } \\
\text { grants, } \\
\text { \& } \\
\text { HRTC } \\
-\quad \text { long } \\
\text { run } \\
\text { (E) }\end{array}$ & $\begin{array}{l}\text { With } \\
\text { all } \\
\text { grants } \\
-\quad \text { long } \\
\text { run }\end{array}$ \\
\hline (1) null & 0.243 & 0.364 & 0.477 & 0.591 & - & - \\
\hline$(2)<90$ AFUE & 0.001 & 0.002 & 0.007 & 0.011 & - & - \\
\hline (3) 90-91 AFUE & 0.002 & 0.005 & 0.014 & 0.018 & 0.056 & 0.003 \\
\hline (4) $\geq 92$ AFUE w/o DC & 0.021 & 0.036 & 0.052 & 0.066 & 0.191 & 0.029 \\
\hline (5) 92-93 AFUE + DC & 0.064 & 0.061 & 0.053 & 0.055 & 0.138 & 0.085 \\
\hline (6) $\geq 94$ AFUE + DC & 0.125 & 0.102 & 0.077 & 0.051 & 0.118 & 0.164 \\
\hline (7) $\geq 95$ AFUE + DC & 0.544 & 0.429 & 0.321 & 0.207 & 0.497 & 0.722 \\
\hline
\end{tabular}

Table 4: Greenhouse gas emissions due to the EcoEnergy program (Mt of CO2)

\begin{tabular}{lll|ll}
\hline & Short run & & Long run \\
\hline & $\begin{array}{l}\text { With } \\
\text { subsidies }\end{array}$ & $\begin{array}{l}\text { Without } \\
\text { subsidies }\end{array}$ & $\begin{array}{l}\text { With } \\
\text { subsidies }\end{array}$ & $\begin{array}{l}\text { Without } \\
\text { subsidies }\end{array}$ \\
\hline null & 0.59 & 1.48 & - & - \\
$<90$ AFUE & 0.00 & 0.03 & - & - \\
90-91 AFUE & 0.01 & 0.04 & 0.01 & 0.12 \\
>=92 AFUE without DC motor & 0.05 & 0.15 & 0.06 & 0.41 \\
92-93 AFUE with DC motor & 0.14 & 0.12 & 0.18 & 0.29 \\
94 AFUE with DC motor & 0.26 & 0.11 & 0.34 & 0.25 \\
>=95 AFUE with DC motor & 1.15 & 0.46 & 1.50 & 1.05 \\
\hline & & & & \\
Total & 2.19 & 2.38 & 2.09 & 2.12 \\
& & & & \\
Lifetime (15 years) & 32.87 & 35.72 & 31.35 & 31.85 \\
\hline & & & & \\
Difference & & 2.86 & & 0.50 \\
\hline
\end{tabular}


Table 5: Cost effectiveness of the furnace retrofit grants

\begin{tabular}{lll}
\hline & Excluding HRTC & Including HRTC \\
\hline Expenditure $(\$ \mathrm{M})$ & 287.2 & 431.3 \\
Short run cost $(\$ / \mathrm{t} \mathrm{CO})$ & 101 & 151 \\
Long run cost $\left(\$ / \mathrm{tCO}_{2}\right)$ & 574 & 861 \\
\hline
\end{tabular}




\section{Appendix 1: Retrofit program details}

Canadian Federal and Provincial Retrofit Subsidies (\$C)

Natural Gas Furnaces

April 2007 - April 2012

(All figures are for the first system claimed only.)

Effective: April 1, 2007

D audit or $E$ audit

\begin{tabular}{|llllllll|}
\hline new furnace type & federal & BC (1) & BC (2) & AL & SK & MAN & ONT \\
<90 AFUE & & & & & & & \\
90-91 AFUE & 0 & 0 & 0 & 0 & 0 & 0 & 0 \\
$\geq 92$ AFUE without DC motor & 300 & 0 & 0 & 0 & 300 & 245 & 300 \\
92-93 AFUE + DC motor & 500 & 0 & 0 & 0 & 500 & 245 & 500 \\
94 AFUE + DC motor (A) & 500 & 0 & 0 & 0 & 500 & 245 & 500 \\
94 AFUE + DC motor (B) & 500 & 0 & 0 & 0 & 500 & 245 & 500 \\
$\geq 95$ AFUE + DC motor (A) & 500 & 0 & 0 & 0 & 500 & 245 & 500 \\
$\geq 95$ AFUE + DC motor (B) & 500 & 0 & 0 & 0 & 500 & 245 & 500 \\
\hline
\end{tabular}

A: first time condensing furnace

$\mathrm{B}$ : replaces a condensing furnace

$\mathrm{BC}(1)$ : BC Interior and Northern

BC(2): BC South Coastal

Note: Manitoba Hydro's incentive was introduced November 1, 2005.

Effective: January 1, 2008

D audit or $E$ audit (regardless of date of $D$ audit)

\begin{tabular}{|llllllll|}
\hline new furnace type & federal & BC (1) & BC (2) & AL & SK & MAN & ONT \\
& & & & & & & \\
<90 AFUE & 0 & 0 & 0 & 0 & 0 & 0 & 0 \\
90-91 AFUE & 300 & 0 & 0 & 0 & 300 & 0 & 300 \\
$\geq 92$ AFUE without DC motor & 300 & 0 & 0 & 0 & 300 & 0 & 300 \\
92-93 AFUE + DC motor & 500 & 0 & 0 & 0 & 500 & 245 & 500 \\
94 AFUE + DC motor (A) & 500 & 0 & 0 & 0 & 500 & 245 & 500 \\
94 AFUE + DC motor (B) & 500 & 0 & 0 & 0 & 500 & 245 & 500 \\
$\geq 95$ AFUE + DC motor (A) & 500 & 0 & 0 & 0 & 500 & 245 & 500 \\
$\geq 95$ AFUE + DC motor (B) & 500 & 0 & 0 & 0 & 500 & 245 & 500 \\
\hline
\end{tabular}


Effective: April 1, 2008

$D$ audit or $E$ audit (regardless of date of $D$ audit)

\begin{tabular}{|c|c|c|c|c|c|c|c|}
\hline new furnace type & federal & $\mathrm{BC}(1)$ & $\mathrm{BC}(2)$ & $\mathrm{AL}$ & SK & MAN & ONT \\
\hline$<90$ AFUE & 0 & 0 & 0 & 0 & 0 & 0 & 0 \\
\hline 90-91 AFUE & 300 & 0 & 0 & 0 & 300 & 0 & 300 \\
\hline$\geq 92$ AFUE without DC motor & 300 & 0 & 0 & 0 & 300 & 0 & 300 \\
\hline 92-93 AFUE + DC motor & 500 & 860 & 580 & 0 & 500 & 245 & 500 \\
\hline 94 AFUE + DC motor (A) & 500 & 860 & 580 & 0 & 500 & 245 & 500 \\
\hline 94 AFUE + DC motor (B) & 500 & 860 & 580 & 0 & 500 & 245 & 500 \\
\hline$\geq 95$ AFUE + DC motor $(A)$ & 500 & 1130 & 770 & 0 & 500 & 245 & 500 \\
\hline$\geq 95$ AFUE + DC motor (B) & 500 & 1130 & 770 & 0 & 500 & 245 & 500 \\
\hline
\end{tabular}

\section{Effective: July 1, 2008}

\section{$D$ audit or $E$ audit (regardless of date of $D$ audit)}

\begin{tabular}{|c|c|c|c|c|c|c|c|}
\hline new furnace type & federal & $\mathrm{BC}(1)$ & $\mathrm{BC}(2)$ & $A L$ & SK & MAN & ONT \\
\hline$<90$ AFUE & 0 & 0 & 0 & 0 & 0 & 0 & 0 \\
\hline 90-91 AFUE & 300 & 0 & 0 & 0 & 300 & 0 & 300 \\
\hline$\geq 92$ AFUE without DC motor & 300 & 0 & 0 & 0 & 300 & 0 & 300 \\
\hline 92-93 AFUE + DC motor & 500 & 860 & 580 & 0 & 500 & 500 & 500 \\
\hline 94 AFUE + DC motor (A) & 500 & 860 & 580 & 0 & 500 & 500 & 500 \\
\hline 94 AFUE + DC motor (B) & 500 & 860 & 580 & 0 & 500 & 500 & 500 \\
\hline$\geq 95$ AFUE + DC motor $(A)$ & 500 & 1130 & 770 & 0 & 500 & 500 & 500 \\
\hline$\geq 95$ AFUE + DC motor (B) & 500 & 1130 & 770 & 0 & 500 & 500 & 500 \\
\hline
\end{tabular}

Note: three-month special offer from Manitoba Hydro - increase from 245 to 500.

\section{Effective: October 13, 2008}

D audit or $E$ audit (regardless of date of $D$ audit)

\begin{tabular}{|c|c|c|c|c|c|c|c|}
\hline new furnace type & federal & $\mathrm{BC}(1)$ & $\mathrm{BC}(2)$ & $\mathrm{AL}$ & SK & MAN & ONT \\
\hline$<90$ AFUE & 0 & 0 & 0 & 0 & 0 & 0 & 0 \\
\hline 90-91 AFUE & 300 & 0 & 0 & 0 & 300 & 0 & 300 \\
\hline$\geq 92$ AFUE without DC motor & 300 & 0 & 0 & 0 & 300 & 0 & 300 \\
\hline 92-93 AFUE + DC motor & 500 & 860 & 580 & 0 & 500 & 245 & 500 \\
\hline 94 AFUE + DC motor (A) & 500 & 860 & 580 & 0 & 500 & 245 & 500 \\
\hline 94 AFUE + DC motor (B) & 500 & 860 & 580 & 0 & 500 & 245 & 500 \\
\hline$\geq 95$ AFUE + DC motor (A) & 500 & 1130 & 770 & 0 & 500 & 245 & 500 \\
\hline$\geq 95$ AFUE + DC motor (B) & 500 & 1130 & 770 & 0 & 500 & 245 & 500 \\
\hline
\end{tabular}


Effective: March 30, 2009

$D$ audit or $E$ audit (regardless of date of $D$ audit)

\begin{tabular}{|llllllll|}
\hline new furnace type & federal & BC (1) & BC (2) & AL & SK & MAN & ONT \\
<90 AFUE & 0 & 0 & 0 & 0 & 0 & 0 & 0 \\
90-91 AFUE & 0 & 0 & 0 & 0 & 0 & 0 & 0 \\
$\geq 92$ AFUE without DC motor & 375 & 0 & 0 & 400 & 300 & 0 & 375 \\
92-93 AFUE + DC motor & 625 & 860 & 580 & 500 & 500 & 245 & 625 \\
94 AFUE + DC motor (A) & 790 & 860 & 580 & 500 & 630 & 245 & 790 \\
94 AFUE + DC motor (B) & 650 & 860 & 580 & 500 & 520 & 245 & 650 \\
$\geq 95$ AFUE + DC motor (A) & 790 & 1130 & 770 & 500 & 630 & 245 & 790 \\
$\geq 95$ AFUE + DC motor (B) & 650 & 1130 & 770 & 500 & 520 & 245 & 650 \\
\hline
\end{tabular}

\section{Effective: August 17, 2009}

D audit or E audit (D audit on or after August 17, 2009)

\begin{tabular}{|llllllll|}
\hline new furnace type & federal & BC (1) & BC (2) & AL & SK & MAN & ONT \\
<90 AFUE & 0 & 0 & 0 & 0 & 0 & 0 & 0 \\
90-91 AFUE & 0 & 0 & 0 & 0 & 0 & 0 & 0 \\
$\geq 92$ AFUE without DC motor & 375 & 0 & 0 & 400 & 300 & 0 & 375 \\
92-93 AFUE + DC motor & 625 & 0 & 0 & 500 & 500 & 245 & 625 \\
94 AFUE + DC motor (A) & 790 & 0 & 0 & 500 & 630 & 245 & 790 \\
94 AFUE + DC motor (B) & 650 & 0 & 0 & 500 & 520 & 245 & 650 \\
$\geq 95$ AFUE + DC motor (A) & 790 & 0 & 0 & 500 & 630 & 245 & 790 \\
$\geq 95$ AFUE + DC motor (B) & 650 & 0 & 0 & 500 & 520 & 245 & 650 \\
\hline
\end{tabular}

E audit (D audit prior to August 17, 2009)

\begin{tabular}{|c|c|c|c|c|c|c|c|}
\hline new furnace type & federal & $\mathrm{BC}(1)$ & $\mathrm{BC}(2)$ & $\mathrm{AL}$ & SK & MAN & ONT \\
\hline$<90$ AFUE & 0 & 0 & 0 & 0 & 0 & 0 & 0 \\
\hline 90-91 AFUE & 0 & 0 & 0 & 0 & 0 & 0 & 0 \\
\hline$\geq 92$ AFUE without DC motor & 375 & 0 & 0 & 400 & 300 & 0 & 375 \\
\hline 92-93 AFUE + DC motor & 625 & 860 & 580 & 500 & 500 & 245 & 625 \\
\hline 94 AFUE + DC motor (A) & 790 & 860 & 580 & 500 & 630 & 245 & 790 \\
\hline 94 AFUE + DC motor (B) & 650 & 860 & 580 & 500 & 520 & 245 & 650 \\
\hline$\geq 95$ AFUE + DC motor (A) & 790 & 1130 & 770 & 500 & 630 & 245 & 790 \\
\hline$\geq 95$ AFUE + DC motor (B) & 650 & 1130 & 770 & 500 & 520 & 245 & 650 \\
\hline
\end{tabular}


Effective: January 1, 2010

$D$ audit or $E$ audit (regardless of date of $D$ audit)

\begin{tabular}{|c|c|c|c|c|c|c|c|}
\hline new furnace type & federal & $\mathrm{BC}(1)$ & $B C(2)$ & $A L$ & SK & MAN & ONT \\
\hline$<90$ AFUE & 0 & 0 & 0 & 0 & 0 & 0 & 0 \\
\hline 90-91 AFUE & 0 & 0 & 0 & 0 & 0 & 0 & 0 \\
\hline$\geq 92$ AFUE without DC motor & 375 & 0 & 0 & 400 & 300 & 0 & 375 \\
\hline 92-93 AFUE + DC motor & 625 & 860 & 580 & 500 & 500 & 0 & 625 \\
\hline 94 AFUE + DC motor (A) & 790 & 860 & 580 & 500 & 630 & 0 & 790 \\
\hline 94 AFUE + DC motor (B) & 650 & 860 & 580 & 500 & 520 & 0 & 650 \\
\hline$\geq 95$ AFUE + DC motor $(A)$ & 790 & 1130 & 770 & 500 & 630 & 0 & 790 \\
\hline$\geq 95$ AFUE + DC motor (B) & 650 & 1130 & 770 & 500 & 520 & 0 & 650 \\
\hline
\end{tabular}

Effective: April 1, 2010

\section{D audit or $E$ audit (D audit on or after April 1, 2010)}

\begin{tabular}{|c|c|c|c|c|c|c|c|}
\hline new furnace type & federal & $\mathrm{BC}(1)$ & $\mathrm{BC}(2)$ & $\mathrm{AL}$ & SK & MAN & ONT \\
\hline$<90$ AFUE & 0 & 0 & 0 & 0 & 0 & 0 & 0 \\
\hline 90-91 AFUE & 0 & 0 & 0 & 0 & 0 & 0 & 0 \\
\hline$\geq 92$ AFUE without DC motor & 0 & 0 & 0 & 400 & 300 & 0 & 375 \\
\hline 92-93 AFUE + DC motor & 0 & 860 & 580 & 500 & 500 & 0 & 625 \\
\hline 94 AFUE + DC motor (A) & 0 & 860 & 580 & 500 & 630 & 0 & 790 \\
\hline 94 AFUE + DC motor (B) & 0 & 860 & 580 & 500 & 520 & 0 & 650 \\
\hline$\geq 95$ AFUE + DC motor (A) & 0 & 1130 & 770 & 500 & 630 & 0 & 790 \\
\hline$\geq 95$ AFUE + DC motor (B) & 0 & 1130 & 770 & 500 & 520 & 0 & 650 \\
\hline
\end{tabular}

E audit (D audit prior to April 1, 2010)

\begin{tabular}{|c|c|c|c|c|c|c|c|}
\hline new furnace type & federal & $\mathrm{BC}(1)$ & $\mathrm{BC}(2)$ & $\mathrm{AL}$ & SK & MAN & ONT \\
\hline$<90$ AFUE & 0 & 0 & 0 & 0 & 0 & 0 & 0 \\
\hline 90-91 AFUE & 0 & 0 & 0 & 0 & 0 & 0 & 0 \\
\hline$\geq 92$ AFUE without DC motor & 375 & 0 & 0 & 400 & 300 & 0 & 375 \\
\hline 92-93 AFUE + DC motor & 625 & 860 & 580 & 500 & 500 & 0 & 625 \\
\hline 94 AFUE + DC motor (A) & 790 & 860 & 580 & 500 & 630 & 0 & 790 \\
\hline 94 AFUE + DC motor (B) & 650 & 860 & 580 & 500 & 520 & 0 & 650 \\
\hline$\geq 95$ AFUE + DC motor (A) & 790 & 1130 & 770 & 500 & 630 & 0 & 790 \\
\hline$\geq 95$ AFUE + DC motor (B) & 650 & 1130 & 770 & 500 & 520 & 0 & 650 \\
\hline
\end{tabular}


Effective: April 1, 2011

$D$ audit or $E$ audit (regardless of date of $D$ audit)

\begin{tabular}{|llllllll|}
\hline new furnace type & federal & BC (1) & BC (2) & AL & SK & MAN & ONT \\
<90 AFUE & 0 & 0 & 0 & 0 & 0 & 0 & 0 \\
90-91 AFUE & 0 & 0 & 0 & 0 & 0 & 0 & 0 \\
$\geq 92$ AFUE without DC motor & 0 & 0 & 0 & 400 & 0 & 0 & 0 \\
92-93 AFUE + DC motor & 0 & 0 & 0 & 500 & 0 & 0 & 0 \\
94 AFUE + DC motor (A) & 0 & 0 & 0 & 500 & 0 & 0 & 0 \\
94 AFUE + DC motor (B) & 0 & 0 & 0 & 500 & 0 & 0 & 0 \\
$\geq 95$ AFUE + DC motor (A) & 0 & 600 & 500 & 500 & 650 & 0 & 0 \\
$\geq 95$ AFUE + DC motor (B) & 0 & 600 & 500 & 500 & 650 & 0 & 0 \\
\hline
\end{tabular}

Effective: June 6, 2011

D audit or $E$ audit (regardless of date of $D$ audit)

\begin{tabular}{|llllllll|}
\hline new furnace type & federal & BC (1) & BC (2) & AL & SK & MAN & ONT \\
<90 AFUE & 0 & 0 & 0 & 0 & 0 & 0 & 0 \\
90-91 AFUE & 0 & 0 & 0 & 0 & 0 & 0 & 0 \\
$\geq 92$ AFUE without DC motor & 375 & 0 & 0 & 400 & 0 & 0 & 0 \\
92-93 AFUE + DC motor & 625 & 0 & 0 & 500 & 0 & 0 & 0 \\
94 AFUE + DC motor (A) & 790 & 0 & 0 & 500 & 0 & 0 & 0 \\
94 AFUE + DC motor (B) & 650 & 0 & 0 & 500 & 0 & 0 & 0 \\
$\geq 95$ AFUE + DC motor (A) & 790 & 600 & 500 & 500 & 650 & 0 & 0 \\
$\geq 95$ AFUE + DC motor (B) & 650 & 600 & 500 & 500 & 650 & 0 & 0 \\
\hline
\end{tabular}


Effective: January 31, 2012

$D$ audit or $E$ audit ( $D$ audit on or after January 31, 2012)

\begin{tabular}{|llllllll|}
\hline new furnace type & federal & BC (1) & BC (2) & AL & SK & MAN & ONT \\
& & & & & & & \\
<90 AFUE & 0 & 0 & 0 & 0 & 0 & 0 & 0 \\
90-91 AFUE & 0 & 0 & 0 & 0 & 0 & 0 & 0 \\
$\geq 92$ AFUE without DC motor & 0 & 0 & 0 & 400 & 0 & 0 & 0 \\
92-93 AFUE + DC motor & 0 & 0 & 0 & 500 & 0 & 0 & 0 \\
94 AFUE + DC motor (A) & 0 & 0 & 0 & 500 & 0 & 0 & 0 \\
94 AFUE + DC motor (B) & 0 & 0 & 0 & 500 & 0 & 0 & 0 \\
$\geq 95$ AFUE + DC motor (A) & 0 & 600 & 500 & 500 & 650 & 0 & 0 \\
$\geq 95$ AFUE + DC motor (B) & 0 & 600 & 500 & 500 & 650 & 0 & 0 \\
\hline
\end{tabular}

E audit (D audit prior to January 31, 2012)

\begin{tabular}{|llllllll|}
\hline new furnace type & federal & BC (1) & BC (2) & AL & SK & MAN & ONT \\
& & & & & & & \\
<90 AFUE & 0 & 0 & 0 & 0 & 0 & 0 & 0 \\
90-91 AFUE & 0 & 0 & 0 & 0 & 0 & 0 & 0 \\
$\geq 92$ AFUE without DC motor & 375 & 0 & 0 & 400 & 0 & 0 & 0 \\
92-93 AFUE + DC motor & 625 & 0 & 0 & 500 & 0 & 0 & 0 \\
94 AFUE + DC motor (A) & 790 & 0 & 0 & 500 & 0 & 0 & 0 \\
94 AFUE + DC motor (B) & 650 & 0 & 0 & 500 & 0 & 0 & 0 \\
$\geq 95$ AFUE + DC motor (A) & 790 & 600 & 500 & 500 & 650 & 0 & 0 \\
$\geq 95$ AFUE + DC motor (B) & 650 & 600 & 500 & 500 & 650 & 0 & 0 \\
\hline
\end{tabular}

Effective: April 1, 2012

$D$ audit or $E$ audit (regardless of date of $D$ audit)

\begin{tabular}{|c|c|c|c|c|c|c|c|}
\hline new furnace type & federal & $B C(1)$ & $B C(2)$ & AL & SK & MAN & ONT \\
\hline$<90$ AFUE & 0 & 0 & 0 & 0 & 0 & 0 & 0 \\
\hline 90-91 AFUE & 0 & 0 & 0 & 0 & 0 & 0 & 0 \\
\hline$\geq 92$ AFUE without DC motor & 0 & 0 & 0 & 0 & 0 & 0 & 0 \\
\hline 92-93 AFUE + DC motor & 0 & 0 & 0 & 0 & 0 & 0 & 0 \\
\hline $94 \mathrm{AFUE}+\mathrm{DC}$ motor (A) & 0 & 0 & 0 & 0 & 0 & 0 & 0 \\
\hline 94 AFUE + DC motor (B) & 0 & 0 & 0 & 0 & 0 & 0 & 0 \\
\hline$\geq 95$ AFUE + DC motor (A) & 0 & 600 & 500 & 0 & 650 & 0 & 0 \\
\hline$\geq 95 \mathrm{AFUE}+\mathrm{DC}$ motor (B) & 0 & 600 & 500 & 0 & 650 & 0 & 0 \\
\hline
\end{tabular}




\section{Appendix 2: Construction of the data set}

\section{Constructing the sample}

Data on audits performed to support the EEH program was obtained from Natural Resources Canada. We received separate files for all pre-retrofit and post-retrofit audits conducted between April 1, 2007 and March 31, 2011. Each household is identified with a unique identification number in the preretrofit and post-retrofit files. We merged the two sets of files using these identification numbers, keeping all households that received both a pre-retrofit audit and post-retrofit audit.

We performed a number of operations to clean the EEH program database. First, we dropped observations which had dates incorrectly recorded (i.e., dates that fell outside of the program window, or dates which implied a span of more than 18 months between initial and final audits, which are not permitted by the program). In our sample, 79 households had the pre-retrofit audit date incorrectly recorded, and 3,383 households had the post-retrofit date incorrectly recorded. A further 4,494 households had a pre-retrofit date coded later than a post-retrofit date, and 33,544 had a span of larger than 18 months between pre- and post-retrofits. Next, we dropped 2,703 households that reported not using natural gas as a primary heating fuel, or that reported a nil expenditure on natural gas. Next, we dropped 201 households that reported a gas consumption of over 15,000 GJ per year; these were outliers in the data set and likely reflected incorrect units in the data. We then calculated the natural gas price as the expenditure on natural gas divided by the consumption in physical units. We dropped 22,166 households for which the imputed natural gas price was less than $\$ 0.2 / \mathrm{m}^{3}$ or above $\$ 0.8 / \mathrm{m}$, which is the range of observed natural gas prices during the period for which we have data. Once again, we believe that these observations were likely entered in the database in incorrect units. Finally, we dropped 1,091 observations in provinces east of Ontario, and 246 observations with missing values for furnace efficiency. This leaves us with 328,688 observations, which we use to estimate the models in the text. Table 6 summarizes these operations and their effect on the sample size.

In a few cases the furnace annual fuel utilization efficiency is missing. However, we have rated (peak) energy efficiency for all records, and we use this to impute furnace AFUE for those furnaces with missing records. Because there is an extremely close fit between rated energy efficiency and AFUE, this imputation should not introduce significant measurement error.

\section{Table 6: Developing the sample}

\begin{tabular}{|l|l|}
\hline Description & Number of observations \\
\hline Full EEH program sample & 396,595 \\
\hline Drop incorrectly coded dates & 355,095 \\
\hline Drop if no natural gas for heating & 352,392 \\
\hline Drop if gas consumption $>15,000 \mathrm{~m}^{3}$ & 352,191 \\
\hline Drop if imputed natural gas price incorrect & 330,025 \\
\hline Drop if not in Ontario and West & 328,934 \\
\hline Drop if missing furnace efficiency & 328,688 \\
\hline
\end{tabular}

Using geographic identifiers (6 digit postal codes), we merge the EEH program database with the census database. Our census information is aggregated to the level of census dissemination areas, and we link these to postal codes with a link file produced by Statistics Canada. A number of observations have missing geographical identifiers, or else record only the forward sortation area (first three digits of postal code). We drop these observations when we estimate models including income as a covariate. Finally, we then merge the EEH database with the database that we constructed on grant availability (given in Appendix 1). This merge is based on the date of the audit, as described in the text. 


\section{Fan type and the measurement of AFUE}

Our use of the adjustment factor $A F U E_{\text {original }} / A F U E_{i}$ to calculate operating costs in (8) is complicated by the fact that the three highest efficiency alternatives also include brushless DC fan motors which provide efficiency benefits not captured in the measurement of AFUE. This distinction relates to the amount of electricity consumed in the operation of the fan rather than consumption of natural gas by the furnace.

In order to address this problem, we calculate the expected reduction in the total operating cost of a furnace (cost of natural gas plus cost of the electricity) when switching from a high efficiency furnace to the same furnace with a DC fan motor. The percentage reduction in total cost can be used to adjust the AFUE in an equivalent manner.

To estimate the impact of a DC motor on the total operating cost of a furnace, we refer to Gusdorf et al. (2003). These authors conducted a controlled experiment on the effect of DC motors in a test facility in Ottawa (Canadian Centre for Housing Technology) and then simulated full-year results for four cities Winnipeg, Toronto, Ottawa, and Moncton. We focus our attention on the results for Toronto and Winnipeg since our sample covers Ontario and the western provinces. The authors considered different combinations of building type and age, efficiency of the furnace, presence of central air conditioning, and use of continual circulation. For our purposes, we focus on $A F U E=92$ and a "typical existing" detached house with central air conditioning. We consider the impacts of a DC motor on total operating cost for Toronto and Winnipeg both with and without continual circulation (i.e. four combinations to consider). The prices of electricity and natural gas are 8.45 cents per $\mathrm{kWh}$ and 44.94 cents per $\mathrm{m}^{3}$ respectively in Toronto and 5.59 cents per $\mathrm{kWh}$ and 36.96 cents per $\mathrm{m}^{3}$ respectively in Winnipeg. ${ }^{31}$ We arrive at an average cost savings over the four scenarios of 4.9 percent. We use this value to gross up the AFUE value of alternatives 5, 6, and 7 (high, extra-high, and ultra-high efficiency). For example, the adjusted AFUE value for the high efficiency furnace (alternative 5) is $A F U E_{5}=92+4=96$ (we use the lowest AFUE value in the range for each alternative). This value is then used in the adjustment factor $A F U E_{\text {original }} / A F U E_{5}$ to calculate the operating cost of this alternative. For houses without central air conditioning, we use a value of 2 .

\section{Home renovation tax credit (HRTC)}

The Home Renovation Tax Credit (HRTC) was implemented as a temporary stimulus program during the recession in 2009. During the 2009 tax year, Canadian households were eligible to claim a non-refundable tax credit for home renovation expenditures in the calculation of personal income tax. The credit was based on the portion of expenditures in excess of $\$ 1,000$ up to $\$ 10,000$ (i.e. a maximum base for the credit of $\$ 9,000$ ). This amount was multiplied by the credit rate of 0.15 (i.e. $15 \%$ ). We estimate the value of the HRTC for all furnace alternatives using data on furnace costs provided by Caneta Research Inc. on the retail purchase cost of furnaces in southwestern Ontario. To estimate the value of the HRTC, we subtract $\$ 1000$ from the furnace cost and then multiply the difference by the credit rate 0.15 (see above). Because some households have little income tax payable and because some households conduct multiple renovations such that the furnace renovation does not impact HRTC magnitude, our estimate will be an upper bound on the size of the HRTC. We have conducted additional regressions that multiply our estimated HRTC value by a constant that ranges from 0 to 1 , and find that the coefficients in our regression are essentially unchanged.

The determination of eligibility for the tax credit is based on the 2009 tax year. More precisely, the federal income tax return 2009 (Schedule 12) defines eligible expenses as "those incurred after January 27, 2009 and before February 1, 2010". However, the only requirement for eligibility was expenditure, not installation. Therefore, many households that claimed the tax credit were able to purchase the furnace before February 1, 2010, with installation and retrofit audits coming later. For this reason, we expect

\footnotetext{
${ }^{31}$ See Gusdorf, et al. (2003) for other assumptions in their simulations, such as thermostat setting and detailed building characteristics. The raw data for this exercise are taken from their Tables F5, F11, F13, and F19.
} 
many households that claimed the tax credit will show up in the retrofit dataset in 2010 rather than 2009. In fact, some households claiming the tax credit may also show up in the retrofit dataset in 2011, since the rules of the EcoEnergy program allowed 18 months between the pre-retrofit audit and post-retrofit audit. Therefore, we assign the HRTC to all observations with post-retrofit audits between February 2009 and March 2011 (the latter date was the closing date of the first federal EcoEnergy program).

\section{Sample weights}

The EEH dataset presents a stratified sample of households' choices regarding furnace replacement during the program timeframe (i.e. choice-based sample). We construct sample weights in the following manner.

To begin, we obtain the total number of single-family dwellings in our sample area (BC, Alberta, Saskatchewan, Manitoba, Ontario) from the 2006 Census. From the EEH dataset, we identify the sample share that uses natural gas as its primary heating fuel. We apply this share to the number of single-family dwellings from the Census to obtain an estimate of the population of households which heat with natural gas in our sample area.

Replacement alternatives 4-7 were eligible for subsidies throughout the timeframe. Therefore, we assume the EEH dataset includes the entire population of households which selected one of these alternatives. Alternative 3 was eligible for subsidies only between April 1, 2007, and March 29, 2009. Again we assume the EEH dataset includes the entire population of households which selected this alternative during this interval. We subtract these population values from the population of households with gas connections, to arrive at the population of households which chose furnace alternatives which were not eligible for subsidies.

Alternatives 1 and 2 were not eligible for subsidies at any time during our timeframe. Similarly, alternative 3 was not eligible for subsidies after March 30, 2009. Nonetheless, the EEH dataset includes observations for these alternatives for households which claimed subsidies for other eligible renovations (e.g. windows, insulation). We assume that households' choices of other renovations were uncorrelated with choices regarding furnace. It follows that the EEH dataset provides a random sample of these furnace alternatives. We use the relative sample shares of these alternatives as an estimate of the relative population shares (since the alternatives have been sampled randomly). We apply these shares to the population of households with non-eligible furnace choices.

In this manner, we obtain an estimate of the allocation of the population among furnace alternatives, from which we calculate the necessary population shares. 